\title{
Sosyal Medya Kullanım Bozukluğu Ölçeği’nin Türk Kültürüne Uyarlanması: Geçerlik ve Güvenirlik Çalışması
}

\section{The Adaptation of the Social Media Disorder Scale to Turkish Culture: Validity and Reliability Study}

\author{
Hakan SARIÇAM*
}

\author{
Fatıma Firdevs ADAM KARDUZ**
}

\begin{abstract}
$\ddot{O} \mathbf{z}$
Bu çalışmada Sosyal Medya Kullanım Bozukluğu Ölçeği’nin (SMKBÖ-9) Türk ergenlerde geçerlik ve güvenirliğini test etmek ve psikometrik özelliklerini incelemek amaçlanmıştır. Araştırma kapsamına yaşları 13 ile 18 arasında değişen üç farklı çalışma grubunda yer alan toplam $586(202+204+180)$ ergen alınmıştır. Açımlayıcı faktör analizi sonuçlarına göre SMKBÖ’nün Türkçe formunun orijinalindeki gibi tek boyuta sahip olduğu ve bu tek boyutlu yapının ölçtüğü özellikle ilgili toplam varyansın \%48.11'ini açıladığı görülmüştür. Doğrulayıcı faktör analizi sonucu ölçeğin uyum iyiliği değerleri $\chi^{2} / \mathrm{sd}=1.87, \mathrm{RMSEA}=.066, \mathrm{CFI}=.98, \mathrm{GFI}=.98$, $\mathrm{IFI}=.98, \mathrm{NFI}=.96, \mathrm{RFI}=.97$ ve SRMR=.039 olarak hesaplanmıștır. Ayrıca madde faktör yükleri de .35 ile .76 arasında sıralanmaktadır. Eşdeğer ölçek (ölçüt) geçerliği çalışmasında Sosyal Medya Kullanım Bozukluğu Ölçeği ile Young İnternet Bağımlılığı Testi-Kısa Formu ve Ergenler için Akıllı Telefon Bağımlılığı-Kısa Formu arasında sırasıyla $r=.64$, .66 ilişkiler tespit edilmiştir. Cronbach alfa iç tutarlık katsayısı .75, Guttman iki yarı test güvenirlik katsayısı .64 olarak bulunmuştur. Düzeltilmiş madde toplam korelasyon katsayıları .29 ile .73 arasında değişmektedir. Tüm bu sonuçlar, Sosyal Medya Kullanım Bozukluğu Ölçeği’nin Türk ergenlerde kullanılabilecek geçerli ve güvenilir bir ölçme aracı olduğunu göstermiştir.
\end{abstract}

Anahtar Kelimeler: Sosyal medya, bağımlılık, ölçek, geçerlik, güvenirlik.

\begin{abstract}
The present study aimed to test the reliability and validity of Social Media Disorder (SMD-9) Scale in Turkish adolescents and to examine its psychometric properties. Three study groups were conducted among a total of $586(202+204+180)$ Turkish adolescents aged from 13 to 18 . According to explanatory factor analysis results, it was found that the Turkish form of the SMDS had one-dimension just like the original version and the unidimensional scale explained $48.11 \%$ of variance related to the attribute it measured. In confirmatory factor analysis, fit index values were found as $\chi^{2} / \mathrm{df}=1.87$, RMSEA $=.066, \mathrm{CFI}=.98, \mathrm{GFI}=.98, \mathrm{IFI}=.98, \mathrm{NFI}=.96$, $\mathrm{RFI}=.97$, and SRMR $=.039$. Factor loadings ranged from .35 to .76 . In the concurrent validity, the Social Media Disorder Scale had significant relationships with Young's Internet Addiction Test-Short Form and Smart Phone Addiction Scale-Short Form for Adolescent $(r=.64$, .66, respectively). Cronbach alpha internal consistency coefficient was found as .75. Guttman split-half reliability coefficient was found as .64. Corrected item-total correlations ranged from .29 to .73 . Overall results demonstrated that Social Media Disorder Scale can be used for Turkish adolescents as a valid and reliable instrument.
\end{abstract}

Keywords: Social media, addiction, scale, validity, reliability.

\section{GİRIŞ}

Sosyal medya ağları ya da siteleri internet teknolojisinin günlük yaşamımıza kattığı ve her geçen gün kullanıcı sayısının arttığı popüler kültürün öğelerinden biridir. Gittikçe kullanımı artan sosyal medya, karşılıklı konuşmaları geliştirerek insanların iletişim biçimini değiştiren web tabanlı bir

\footnotetext{
*Dr. Öğr. Üyesi, Dumlupınar Üniversitesi, Eğitim Fakültesi, Kütahya, Türkiye, e-posta: hakansaricam@gmail.com, ORCID ID: orcid.org/0000-0002-8723-1199

**Doktora öğrencisi, Sakarya Üniversitesi, Eğitim Bilimleri Enstitüsü, Sakarya, Türkiye, e-posta: karduzfirdevs@gmail.com, ORCID ID: orcid.org/0000-0003-1765-6287
} 
teknolojidir ve temelde kişinin şahsi kullanımlarını, performansını ve üretkenliğini kişiselleştirebilecekleri bir alandır (Cabral, 2011). Teknoloji çağının en temel göstergelerinden biri olan sosyal paylaşım ağları her yaştan her kesimin ilgisini çekmekte; sunulan uygulamalar aracılığıyla sanal dünya reel hayatın önüne geçmektedir (Kırık, Arslan, Çetinkaya, \& Gül 2015). Bunun nedenlerinden biri sosyal ağ sitelerinin (Social Network Sites-SNS), web üzerinden ücretsiz ve kolayca erişilebilir olması ve bunun da kullanıcıları cezbetmesidir. Ayrıca bu sanal ortam, yermekân sınırlaması olmadığı için insanlara birbirleriyle etkileşimde bulunma firsatları oluşturmaktadır (Mahmood \& Farooq, 2014). Buna ek olarak son y1llarda mobil cihaz teknolojisinin hızla büyümesi ve ilerlemesiyle birlikte, geniş kapsamlı mobil veri servislerine erişim kolaylığ düzenli profil güncellemeleri, yorumlara ve mesajlara gerçek zamanlı olarak cevap vermeyi kolaylaştırarak günlük sosyal etkileşimin hızla gelişmesine katkı sağlamaktadır (Otu, 2015). Öte yandan günlük hayatımızda bu kadar hızlı bir şekilde kendine yer bulan sosyal medyanın eğlence, oyun, sosyal etkileşim, bilgiye kolay ulaşma gibi birçok firsat sunmasının yanı sıra tıpkı internet, akıllı telefon, bilgisayar gibi araçlara bağımlılık oluşturulabildiği ve buna bağlı olarak Karpal Tünel Sendromu (KTS) (Collier, 2009), Göz Yorgunluğu Sendromları (Kozeis, 2009; Rosenfield, 2016) gibi sağlık problemleri oluşturma riski taşıdığı söylenebilir.

İlgili literatür incelendiğinde sosyal medyaya ve internete yönelik bağımlılık konusunun sıklıkla ele alındığı görülmektedir (Aboujaoude, 2010; Byun et al., 2009; Douglas et al., 2008; Griffiths, 2013; Kempa, 2015; Kırı ve diğerleri, 2015; Li, Zhang, Li, Zhou, Zhao, \& Wang, 2016; Milani, Osualdella, \& Di Blasio, 2009; Sioni, Burleson, \& Bekerian, 2017; Wang \& Qi, 2017; Yuan et al., 2011). Patolojik internet kullanımı ya da internet kullanım bozukluğu akıllı telefonların akıl almaz yükselişi (Erfanmanesh \& Hosseini, 2015), genetik olarak bağımlılı̆̆a yatkınlık (Kormas, Critselis, Janikian, Kafetzis, \& Tsitsika, 2011), mutsuz olunan gerçek hayattan kaçma arzusu (Ang, Chan, \& Lee, 2017), zihinsel sağlık sorunları (Islam \& Hossin, 2014; Robbins, Gillan, Smith, de Wit, \& Ersche, 2012), utangaç olma (Scealy, Phillips, \& Stevenson, 2002), ebeveyn sosyoekonomik statüsü (Hur, 2006), kişilerarası problemler, sosyal beceri eksikliği (Torrente, Piqueras, Orgilés, \& Espada, 2014), sosyal olma arzusu (Esen \& Siyez, 2011), stresli durumlardan kaçma (Shaw \& Black, 2008) gibi nedenlerden kaynaklanabilmektedir. İnternet bağımlılı̆̆ kavramı ile daha çok çevrimiçi veya çevrimdışı oyun, kumar veya cinsel aktiviteler kastedilir. Kavramın öncüsü Young (1998a) ise internet bağımlılığını bir teknoloji bağımlılığı olarak adlandırmış ve internette geçirilen süreyi ayırıcı tanı olarak ele almıştır. Bununla birlikte internet bağımlılığ 1 kavramsal olarak çok heterojen olduğu için fonksiyonel olmayan ya da bozukluk olarak adlandırılan birçok farklı bileşene sahiptir (Morahan-Martin \& Schumacher, 2000; Starcevic \& Aboujaoude, 2017). Bunlardan bazıları arasında video oyunları, çevrimiçi kumar oyunları ve sosyal medya kullanım süresi (Erfanmanesh \& Hosseini, 2015; Griffiths, 2010; Van Rooij, Schoenmakers, Van den Eijnden, \& Van de Mheen, 2010) gösterilebilir.

İnternet teknolojisinin bir yansıması olarak bilinen sosyal medya sitelerine özellikle ergenler ve gençler yoğun bir şekilde talep gösterirken; gerek Türkiye'de gerekse de dünyada sosyal medya bağımlıların (Aftab, Çelik, \& Sarıçam, 2015; Andreassen, 2015; Andreassen, Pallesen, \& Griffiths, 2017; Caumont, 2014; Chaffey, 2017; Shensa et al., 2017) sayıs1 hızla artmaktadır. Sosyal medya bağımlılığı, internet bağımlılığının evrilmiş bir başka tipi olmasının yanı sıra madde bağımlılığında gözüken benzer belirtilere sahiptir (Griffiths, 2013). Kuss ve Griffiths (2011) bu ortak belirtileri ruh halinde değişimler, duygu durumu çatışmaları, davranışsal, bilişsel ve duygusal olarak zihnin sürekli internet ile meşgul olması, sosyal medya kullanımı kısıtlandığında ya da durdurulduğunda olumsuz fiziksel ve duygusal belirtilerin görülmesi, kişisel ve kişiler arası çatışma yaşanması halinde kullanımın artması şeklinde aktarmıştır. Ryan ve diğerlerinin (2014) yaptı̆̆ 1 araştırmada Facebook kullanımının en önemli nedenlerinin ilişki kurma, zaman geçirme, eğlence ve arkadaşlık olduğu; ayrıca bazı bağımlıların negatif ruh hallerinden kaçmak için Facebook kullandıkları bulunmuştur. Amerikan Psikiyatri Birliği (APA, 2013) DSM-V Tanı Ölçütleri Başvuru El Kitabında patolojik internet/kumar bağımlılığını bir dürtü kontrol bozukluğu ve geçici bağımlılık türü olarak belirtmiştir. Bununla birlikte sosyal medya bağımlılı̆̆ını kapsam dışında bırakması sosyal medya bağımlılığının meşru bir zihinsel bozukluk olmadığı fikrini oluştursa da (Starcevic \& Aboujaoude, 2017) bunun 
aksini iddia eden birtakım çalışmalar da bulunmaktadır (Pantic, 2014; Ryan, Chester, Reece, \& Xenos, 2014; Van den Eijnden, Lemmens \& Valkenburg, 2016).

Sosyal medya bağımlılığının ele alış biçimi incelendiğinde günümüzde sosyal medya bağımlılığının sıradan bir problem olmaktan çıktığı, küresel salgın bir hastalık haline geldiği söylenebilir. Dünyanın dört bir yanındaki insanlar sosyal medyaya fazlasıyla ilgili olabilmekte ve sosyal medyayı kullanırken çok fazla zaman harcayabilmektedirler. Bundan dolayı sosyal medya dünyadaki milyonlarca insanın hayatını olumsuz etkilemektedir (Andreassen, 2015; Khan et al., 2017). İnsanlar artık her yerde, her zaman hatta hareket halindeyken bile mobil cihazlardan sosyal medyaya giriş yapmaktadır. Küresel sosyal medya araştırma raporunda Ocak 2017 itibariyle dünya genelinde 2.789 milyar aktif sosyal medya kullanıcısının olduğu, 2.549 milyar kişinin ise akıllı telefonlarından aktif olarak sosyal medya kullandığı aktarılmaktadır. Yine aynı araştırma bulgularına göre ülkemizde 48 milyon aktif sosyal medya kullanıcısı olduğu, 42 milyon kişinin aktif olarak akıllı telefonlardan sosyal medya kullandıkları tespit edilmiştir. Raporda aktarılan daha da çarpıcı bir bulgu: 1.871 milyon aktif kullanıcısı ile sosyal medya sitelerinin ilk sırasında yer alan Facebook kullanıcılarının \%63'ünden fazlas1 Facebook sitesine günde en az sekiz defa girmektedir (Chaffey, 2017). Vishwanath'ın (2015) belirttiğine göre Facebook'ta bazı insanlar günde 8 saatini harcamaktadır. Yukarıdaki ifadelerden de anlaşılacağı üzere birçok insan için günlük sosyal medya kullanım süresinin, temel fizyolojik gereksinimleri için ayırdığı süreden daha fazla olduğu söylenebilir.

\section{Araştırmanın Önemi ve Amacı}

Sosyal medya kullanımının, günümüzdeki çocukların ve ergenlerin en yaygın faaliyetleri arasında olmas1 (O'Keeffe, 2011), beraberinde problemli internet kullanımı sorununu ortaya çıkarmaktadır (Günlü \& Ceyhan, 2017). Sosyal medya kullanım süresi arttıkça genç yetişkinlerde depresyon (Lin et al., 2016; Moreno et al., 2011; Sarıçam, Tarhan, \& Soyuçok, 2015), anksiyete (Seabrook, Kern, \& Rickard, 2016; Vannucci, Flannery, \& Ohannessian, 2017), stres (Nabi, Prestin, \& So, 2013; Rus \& Tiemensma, 2017), ruminasyon (Davila et al., 2012; Shaw, Timpano, Tran, \& Joormann, 2015), uyku bozukluğu (Levenson et al., 2016; Tavernier \& Willoughby, 2014), sosyal kayg1 (Chiou, Lee, \& Liao, 2015; Dobrean \& Păsărelu, 2016; Sarıçam et al., 2015), narsizim (Andreassen, Pallesen, \& Griffiths, 2017), kıskançlık (Appel, Crusius, \& Gerlach, 2015; Tandoc, Ferrucci, \& Duffy, 2015), akademik başarısızlık (Owusu-Acheaw \& Larson, 2015) gibi duygu, davranış ve kişilik bozukluklarının görülme olasılığı artmaktadır. Bununla birlikte yine sosyal medya kullanımının artması ergenlerde benlik saygılarının düşmesine (Hawi \& Samaha, 2016), olumsuz benlik imaj1 oluşmasına (Dumitrache, Mitrofan \& Petrov, 2012), ruhsal sağlık problemlerine (Best, Manktelow, \& Taylor, 2014; Frost \& Rickwood, 2017; Saraji \& Fini, 2017; Sarıçam, Yaman, \& Çelik, 2016, Wegmann, Stodt, \& Brand, 2015), akademik başarısızlığa (Ahn, 2011; Owusu-Acheaw, \& Laron, 2015), kortizol eksikliğine (Morin-Major et al., 2016) sebep olabilmektedir. Dolayısiyla sosyal medyanın yaygınlaşması göz önüne alındığında, sosyal medyanın davranış bozuklukları, kişilik problemleri, psikolojik sağlik ve akademik performans ile ilişkisinin nedenlerini belirlemek ve açıklamak, sosyal medya kullanımını ve bu problemleri ele alan müdahale yöntemlerini belirlemede kritik önem taşımaktadır.

Her yaş grubundaki bireylerin sosyal medyada fazla zaman geçirmeleri ve buna bağlı olarak kişisel, sosyal, eğitsel ve mesleki sorumluluklarını yerine getirmede problem yaşamaları kaçınılmaz olmaktadır (Aftab, Çelik, \& Sarıçam, 2015; Şahin \& Yağc1, 2017). Benzer durum tüm teknoloji kullanım orijinli bağımlılıklar için söylenebilir. Kırık ve diğerlerinin (2015) yaptığı çalışmada, 14 yaş grubundaki bireylerin sosyal medya bağımlılığı puanları düşük, fakat 17 yaşına kadar yaş arttıkça bağımlılı̆̆ın arttı̆̆ı, 18 yaşında tekrar düşüşe geçtiği bulunmuştur. Ekşi ve Çiftçi'ye (2017) göre ergenlerde problemli internet kullanımının en büyük nedenleri arasında ahlaki olgunluğun düşük olması gelmektedir. Sosyal medyayı kullanan ergenlerde yetişkinlerin fark ettiğinden de fazla risk faktörleri bulunmaktadır. Özellikle bu risk faktörlerine akranlar arası uygunsuz içerik, çevrimiçi gizlilik konularında bilgi eksikliği ve reklam gruplarının dış etkileri alanlarında rastlanılmaktadır (O'Keeffe, 2011). Bu bilgilerden yola çıkarak çocuk ve gençlerin fiziksel, psikolojik ve sosyal sağlıkları açısından uygun ortamlar olmaması nedeniyle anne-babaların sosyal medya sitelerinin 
içinde barındırdığı risklerin farkında olmaları gerekmektedir. Ergenlerin sosyal medyaya ne ölçüde bağımlı olduklarını tespit edip, doğru tanımlayabilmek için geçerlik ve güvenirlik çalışmaları yapılmış ölçeklere ihtiyaç duyulmaktadır.

Türkiye'de konu ile ilgili yapılmış benzer ölçek uyarlama ve geliştirme çalışmaları bulunmaktadır (Otrar \& Argın, 2015; Şahin \& Yağc1, 2017; Şişman Eren, 2014; Türkyılmaz, 2015), fakat sosyal medya bağlamındaki bu ölçme araçları incelendiğinde bir kısmı tutuma yönelik (Otrar \& Argın, 2015), bir kısmı yetişkinlerdeki bağımlılı̆̆ değerlendirmeye yönelik (Şahin \& Yağc1, 2017), bir kısmı kullanım amacına yönelik (Şişman Eren, 2014), bir kısmı da spesifik sosyal medya sitelerine (ör: Facebook bağımlılığı) yöneliktir (Türkyılmaz, 2015).

$\mathrm{Bu}$ çalışmanın amacı, ergenlerin sosyal medya bağımlılıklarının tespit edilmesini sağlayacak Sosyal Medya Kullanım Bozukluğu Ölçeği'ni (SMKBÖ-9) Türkçeye uyarlamaktır. Ölçeğin yukarıdaki ölçme araçlarından farkları şu şekilde sıralanabilir: 1-Ergenlere yönelik olması, 2-Tutumları değerlendirmiyor olması, 3-Maddelerin DSM-IV ve DSM-V tanı kriterleri ve önceki bağımlılık ölçek çalışmalarına (Griffiths, 2005; Griffiths et al., 2016; Griffiths, Kuss, \& Demetrovics, 2014; Lemmens, Valkenburg, \& Gentile, 2015; Lemmens, Valkenburg, \& Peter, 2009; Van Rooij et al., 2010; Yen et al., 2007; Young, 1998a) dayandırılarak hazırlanmas1, 4-Muhtemelen en önemli fark1, madde puanlamasının (derecelendirmesinin) kesin net aralıklar içermesi (Ör: "7"= Günde 40 kereden fazla), bundan dolayı teşhis ve tanılama yapabilmesi, 5-Madde sayısının az olması, 6-Basit ve kolay değerlendirilebilir olması. Dolayısıyla SMKBÖ-9'un Türkiye'deki alanyazına önemli katkılar sağlayacağ düşünülmektedir.

\section{YÖNTEM}

\section{Çalışma Grubu}

Ölçeğin psikometrik özelliklerinin tespiti için bir tanesi büyükşehir, iki tanesi orta ölçekli olmak üzere üç farklı ilden $(202+204+180)$ yaşları 13 ile 18 arasında değişen kolay ulaşılabilirlik örnekleme ile seçilmiş 586 ortaokul ve lise öğrencisinden elde edilen verilerden yararlanılmıştır. Katılımcıların 91'i (\%15.53) 13 yaşında, 80'i (\%13.65) 14 yaşında, 118'i (\%20.14) 15 yaşında, 104'ü (\%17.75) 16 yaşında, 105'i (\% 17.92) 17 yaşında ve 88'i (\%15.02) 18 yaşında olup yaş ortalamas1 15.54'tür (SD=1.65). İlk grupta 113 (\%19.28) k1z ve 89 (\%15.19) erkek, ikinci grupta 108 (\%18.43) kız ve 96 (\%16.38) erkek, üçüncü grupta 66 (\%11.26) kız ve 114 (\%19.45) erkek öğrenci bulunmaktadır. Ergenlerin 549'unun Facebook, WhatsApp, Instagram, Twitter vb sosyal medya sitelerinde en az bir tane hesabı bulunmaktadır. Katılımcıların 37 tanesi herhangi bir sosyal medya hesabının olup olmadığı ile ilgili dönüt vermemiştir. Çalışma grubundan 485 katılımcı sosyal medya sitelerine akıllı telefonlardan, 64 katılımcı ise bilgisayar, tablet, internet kafe gibi araçlar ile ulaşmaktadır.

\section{Veri Toplama Araçları}

\section{Sosyal Medya Kullanım Bozukluğu Ölçeği-SMKBÖ (The Social Media Disorder Scale)}

Ergenlerin sosyal medyaya bağımlılık düzeylerini ölçmek için Van den Eijnden, Lemmens ve Valkenburg (2016) tarafından geliştirilen SMKBÖ, dokuz maddelik kısa ve 27 maddelik uzun olmak üzere iki ayrı formdan oluşmaktadır. Maddeler hazırlanırken genellikle DSM-IV'teki Patolojik Kumar Oynama Bağımlılığı başlığındaki ve DSM-V'teki Internet Kumar Bozuklukları başlığındaki ölçütler temel alınmış ve toplamda dokuz ölçüte (Meşguliyet, dayanma, yoksunluk, ısrar, kaçış, problemler, aldatma, yer değiştirme, çatışma) göre madde havuzu oluşturulmuştur. Dokuz maddelik kısa formda her ölçüt için birer madde; 27 maddelik uzun formda her ölçüt için üçer madde bulunmaktadır. Ölçek " $0=$ Hiçbir zaman"- ile " $7=$ Günde 40 kereden fazla" arasında 8'li derecelendirmeye sahip olup; ölçekten 0 ile 63 arasında puanlar alınmaktadır. Yazarlar ölçeğin geçerlik ve güvenirlik çalışmaları için 3 farklı gruptan yaşları 10-17 arasında değişen toplam 2198 $(724+873+601)$ Hollandalı ergenden çevrimiçi olarak elde ettikleri verilerden yararlanmışlardır. 
Kat1limcilara öncelikle Facebook, WhatsApp, Instagram, YouTube, Twitter vb sosyal medya sitelerinde hesapları olup olmadıkları ile bu hesapları ne kadar sıklıkla ve nasıl kullandıkları sorulmuştur. Yakınsak ve ölçüt geçerliği için Kompulsif Internet Ölçeği, Sosyal Medya Bağımlılığı Ölçeği, Benlik Saygısı Ölçeği, Depresyon Ölçeği, Dikkat Eksikliği Ölçeği, Dürtüsellik Ölçeği ve Yalnızlık Ölçeği kullanılmıştır. Ölçeğin 27 maddelik 9 alt boyutlu uzun formu için ikinci düzey faktör analizi sonucu uyum indeksi değerleri birinci grupta $\chi^{2}(288, \mathrm{n}=724)=672.424, \mathrm{p}<0.001$, CFI $=0.963$, RMSEA $=0.043\left(90 \%\right.$ CI:0.039=0.047), üçüncü grupta $\chi^{2}(288, n=601)=570.681$, $\mathrm{p}<0.001, \mathrm{CFI}=0.973$, RMSEA $=0.040(90 \%$ CI: $0.036=0.045)$ olarak hesaplanmıştır. Cronbach alfa iç tutarlık güvenirlik katsayıları ilk grup için .90 , üçüncü grup için .92 olarak bulunmuştur. Ölçeğin 9 maddelik kısa formu için birinci düzey faktör analizi sonucu uyum indeksi değerleri birinci grupta $\chi^{2}(27, \mathrm{n}=873)=62.852, \mathrm{p}=0.001, \mathrm{CFI}=0.997, \mathrm{RMSEA}=0.041$ (90\% CI:0.028 $\left.=0.055\right)$, üçüncü grupta $\chi^{2}(27, \mathrm{n}=601)=54.129, \mathrm{p}=0.002, \mathrm{CFI}=0.989, \mathrm{RMSEA}=0.041 \quad(90 \%$ CI:0.025=0.057). olarak hesaplanmıştır. Ayrıca Cronbach alfa iç tutarlık güvenirlik katsayıları ilk grup için .76, üçüncü grup için .82 olarak bulunmuştur. Ölçeğin kisa ve uzun formu arasındaki korelasyon katsayısı $r=.94$ 'tür. Kisa formun 238 ergenden 2 ay arayla hesaplanan test tekrar test güvenirlik katsayis1 $r=.50$ olarak hesaplanmıştır. Dokuz maddelik ölçeğin kısa formunun duyarlık ve ayırt edicilik analizlerinde 3 gruptan sosyal medya bağımlısı olan $217(53,101,63)$ ergen seçilmiş ve bu ergenlerden elde edilen verilerden yararlanılmıştır. Duyarlılık katsayıları ilk grup için .59 ile .87 , ikinci grup için .50 ile .79 , üçüncü grup için .47 ile .81 arasında değişmektedir. Ayırt edicilik katsayılanı ise ilk grup için .82 ile .97 , ikinci grup için .83 ile .93 , üçüncü grup için .82 ile .96 arasında sırlanmaktadır (Van den Eijnden, Lemmens, \& Valkenburg, 2016). Tüm bu bulgulara dayanarak ölçeğin sosyal medya kullanım bozukluğunu ölçmede geçerli, güvenilir, hassas ve ayırt ediciliği yüksek bir ölçme aracı olduğu söylenebilir.

\section{Young İnternet Bă̆ımlılı̆̆ Testi Klsa Formu (YIBBT-KF)}

Ergenlerin internet bağımlılığı düzeylerini ölçmek amaciyla kullanılan YIBBT-KF Young (1998a; 1998b) tarafından geliştirilmiş, Pawlikowski, Altstötter-Gleich ve Brand (2013) tarafından kısa forma dönüş̧ürülmüştür. YİBT-KF, 12 maddeden oluşmakta olup beşli Likert (1=Hiçbir zaman, 5=Çok sık) tipi bir ölçektir. Ölçme aracının Türk kültürüne uyarlaması Kutlu, Savcı, Demir ve Aysan (2016) tarafından yapılmıştır. Açımlayıcı faktör analizi (AFA) sonucunda, üniversite öğrencilerinde özdeğeri 4.7 olan ve toplam varyansın \%39.52'sini, ergenlerde ise özdeğeri 5.7 olan ve toplam varyansın \%48.9'unu açıklayan bir yapı elde edilmiştir. Üniversite öğrencilerinde YIBBTKF’nin faktör yükleri .46 ile .72 , ergenlerde ise .56 ile .82 arasında değişmektedir. Doğrulayıcı faktör analizi (DFA) sonucu uyum indeksi değerleri $\chi^{2}=144.93$, sd=52, RMSEA=.072, RMR=.70, $\mathrm{GFI}=.93$, AGFI=.90, CFI=.95 ve $\mathrm{IFI}=.91$ olarak bulunmuştur. Madde faktör yükleri üniversite ögrencilerin de .33 ile .67 arasında siralanmaktadır. Ergenlerde yapılan DFA sonucunda tek boyutlu YIBBT-KF modelinin uyum indeksi değerleri $\chi^{2}=141.93, \mathrm{sd}=51$, RMSEA $=.080, \mathrm{GFI}=.90, \mathrm{CFI}=.90$ ve IFI=.90 olarak saptanmıştır. YIBBT-KF'nin ergenlerde faktör yükleri .49 ile .71 arasında değişmektedir. Cronbach alfa iç tutarlık katsayısı üniversite öğrencilerinde .91 , ergenlerde .86 olarak bulunmuştur. YİBTKF'nin test-tekrar test güvenilirlik (korelasyon) katsayısı üniversite ögrencilerinde .93 , ergenlerde ise .86 olarak bulunmuştur. Ölçme aracının düzeltilmiş madde toplam korelasyon katsayılarının üniversite öğrencilerinde .36 ile .62 arasında, ergenlerde ise .47 ile .65 sıralandığı tespit edilmiştir (Kutlu ve diğerleri, 2016). Bu çalışmada ölçeğin Cronbach alfa iç tutarlık güvenirlik katsayıs1 .81 olarak hesaplanmıştır.

\section{Ergenler için Akıllı Telefon Bağımlılık Ölçeği - Kısa Formu}

Ölçeğin orjinali ergenlerin akıllı telefon bağımlılık düzeylerini ölçmek amacıyla Kwon, Kim, Cho ve Yang (2013) tarafindan geliştirilmiş olup; toplamda 10 madde ve tek boyuttan oluşan beşli Likert tipi (1- Kesinlikle Katılmıyorum, 2- Kismen Katılmıyorum, 3-Kararsızım, 4-Kısmen Katıliyorum, 5Kesinlikle Katılıyorum) bir değerlendirme aracıdır. Ölçeğin Türk kültürüne uyarlaması Akın, Altundağ, Turan ve Akın (2014) tarafından gerçekleştirilmiştir. DFA sonucu ölçeğin uyum indeksi 
değerleri $\chi^{2}=56.92, \mathrm{sd}=31, \mathrm{RMSEA}=.052, \mathrm{NFI}=.96, \mathrm{CFI}=.98, \mathrm{IFI}=.98, \mathrm{RFI}=.94, \mathrm{GFI}=.96$ ve $\mathrm{SRMR}=.040$ olarak bulunmuştur. Ölçeğin Cronbach alfa iç tutarlık güvenirlik katsayısı .88 ve düzeltilmiş madde toplam korelasyonlarının .43 ile .76. arasında sıralandığı görülmüştür (Akın ve diğerleri, 2014). Bu çalışmada ölçeğin Cronbach alfa iç tutarlık güvenirlik katsayısı .79 olarak hesaplanmıştır.

\section{İşlem}

Sosyal Medya Kullanım Bozukluğu Ölçeğinin uyarlama çalışması için 28 Şubat 2017 tarihinde ölçeği geliştiren Regina Van den EIJNDEN ile e-mail yoluyla iletişim kurulmuş ve ölçeğin Türkçeye uyarlanabileceğine ilişkin gerekli izin alınmıştır. Ölçeğin Türkçeye çevrilme süreci belli aşamalardan oluşmaktadır. Öncelikle ölçek maddeleri araştırmacılar tarafindan Türkçeye çevrilmiş ve ilgili alandan yurtdışı doktoralı dokuz uzmana gönderilerek görüş istenmiş; dilsel kapsam eşdeğerliğine bakılmıştır. Aynı uzmanlardan elde edilen uzman görüş formları üzerinde beyin firtınası yöntemi ile anlam ve gramer açısından gerekli düzeltmeler yapılmış ve deneme Türkçe formu elde edilmiştir. Hazırlanan deneme formu, Kişisel Bilgi Formu ve diğer ölçme araçları bir araya getirilerek uygulama formu oluşturulmuş; bu form çoğaltılarak ortaokul ve lise öğrencilerine okul rehber öğretmenleri tarafından dağıtılmıştır. Uygulama sırasında gerekli açıklamalar yapılmış, kendilerine uygun bir şekilde yanıtlamaları için yönerge okunarak açıklanmış, isim yazmalarının zorunlu olmadığı, isteyenlere araştırma sonucu hakkında bilgi verilebileceği açıklanarak, cevaplarda içten olunmasının en doğru sonuca ulaşmayı sağlayacağı ifade edilmiştir. Uygulamalar yaklaşık olarak 15 dakika sürmüştür. Dağıtılan bu formlar toplanarak, verilerin bilgisayar ortamına aktarılması sağlanmıştır.

\section{Verilerin Analizi}

Veri setinin normal dağılım sergileyip sergilemediğini test etmek ve uç değerleri tespit etmek için Kolmogorov-Smirnov, Cook's ve Leverage değerlerine bakılmıştır. Veri setinin normal dağılım sergilemediği ve uç değer olmadığı görülmüştür. SMKBÖ'nün psikometrik özelliklerini tespit etmek için kapsam dil geçerliği, yapı geçerliği, ölçüt bağıntılı geçerlik, ayırt edicilik, iç tutarlık güvenirliği, iki yarı test güvenirliği (eşdeğer yarılar) ve madde analizi yöntemleri kullanılmıştır. SMKBÖ’nün yapı geçerliği için elde edilen veriler üzerinde AFA ve DFA yapılmıştır. Bir veri grubuna faktör analizi uygulanabilmesi için verinin faktör analizine uygunluğu ve örneklemin yeterli olması gerekmektedir (Özdamar, 2013). Bundan dolayı öncelikle Bartlet Küresellik Testi ve Kaiser- Meyer Olkin (KMO) Testi sonuçlarına bakılmıştır. AFA yapılmasının bir diğer nedeni sürecin doğası hakkında kuramı test etmek ve gözlenen değişkenleri kullanarak, sürecin temeli için bir işevuruk tanım yapmaktır (Tabachnick \& Fidell, 2014). DFA kullanılmasının nedeni ise kuramsal olarak ortaya konan faktörleri belirlemede rol oynayan değişkenler ile AFA ile belirlenen faktörleri oluşturan orijinal değişkenler arasında uyumluluk bulunup bulunmadığını DFA ile test etmektir (Özdamar, 2013). DFA uyum indeksleri değerlendirilirken CFI (Comparative Fit IndexKarşılaştırmalı Uyum İndeksi), GFI (Goodness of Fit Index-Düzeltilmiş İyilik Uyum İndeksi), IFI (Incremental Fit Index-Artan Uyum İndeksi), NFI (Normed Fit Index -Normlaştırılmış Uyum İndeksi), RFI (Relative Fit Indix-Göreceli Uyum İndeks), RMSEA (Root Mean Square Error of Approximation-Yaklaşık Hataların Ortalama Karekökü) ve SRMR (Standardized Root Mean Square Residual-Standartize Edilmiş Hataların Ortalama Karelerinin Karekökü) değerlerinden faydalanılmıştır. Modelin iyi uyum kriterleri olarak $\chi^{2} / \mathrm{sd} \leq 3$, CFI, GFI, IFI, NFI, RFI $\geq .90$, RMSEA $\leq .80$ değerleri kabul edilmiştir (Çokluk, Şekercioğlu ve Büyüköztürk, 2010; SchermellehEngel, Moosbrugger, \& Müller, 2003). Thompson'a (2004) göre uyum iyiliği değerleri $\chi^{2} / \mathrm{sd} \leq 2$, CFI, GFI, IFI, NFI, RFI $\geq .95$, RMSEA $\leq .50$ olursa çok iyi uyumu göstermektedir. Ölçüt bağıntılı geçerlik için YİBT-KF ve EATBÖ-KF kullanılmıştır. İç tutarlık güvenirlik testi için Cronbach alfa değeri ve iki yarı test güvenirliği için Spearman-Brown katsayıları (Guttman split-half katsayısı) hesaplanmıştır. Bland ve Altman (1997) Cronbach alfa değerinin karşılaştırma gruplarında .70 ile .80 arasında, klinik uygulamalarda .90 ve üzeri bir değer alması gerektiğini vurgulamıştır. Bununla 
birlikte Spearman-Brown iki yarı test güvenirlik katsayısının .70'ten büyük olması gerektiği aktarılmıştır (Walker, 2006). Madde analizlerinde düzeltilmiş madde toplam korelasyon katsayıları ve alt-üst \%27 değerleri incelenmiştir. Analizlerde güven aralığ olarak \%95 (p<.05) ölçüt alınmış; verilerin çözümlenmesinde SPSS 17 ve Lisrel 9.1 istatistik paket programları kullanılmıştır.

\section{BULGULAR}

Geçerlik çalışmaları kapsamında dil kapsam ve yapı geçerliği sınanmıştır. Güvenirlik çalışmaları kapsamında iç tutarlık güvenirliği ve yarı değer eşler güvenirliği hesaplanmıştır. Bununla birlikte madde analizleri de gözlemlenmiştir.

\section{Dil Kapsam Geçerliği}

Ölçeğin dil kapsam geçerliği çalışmasında Lawshe (1975) ve Davis (1992) teknikleri kullanılmıştır. Lawshe (1975) tekniğinde her bir madde için uzmanlar maddeleri üçlü derecelendirmeyle puanlamaktadır. Kapsam geçerlik oranlar (KGO) değeri, herhangi bir maddeye ilişkin "uygun" görüşünü belirten uzman sayılarının, maddeye ilişkin görüş belirten toplam uzman sayısına oranının 1 eksiği ile elde edilir. Bu bağlamda şimdiki çalışmada dörtlü derecelendirme kullanılmış olsa da "uygundur" diyen uzman sayısı önemli olduğundan Lawshe tekniğini kullanmada bir sakınca görülmemiş̧ir. Uzmanlardan gelen dönütlerde maddelere ait dil kapsam geçerlik oran değerleri 0.78 ile +1.00 arasında sıralanmaktadır. Veneziano ve Hooper'a (1997) göre 9 uzman için KGO değerlerinin $\mathrm{p}<.05$ önem düzeyinde minimum 0.75 olmas1 gerekmektedir. $\mathrm{Bu}$ bağlamda değerlendirildiğinde SMKBÖ'nün dil kapsam geçerliği için kabul edilebilir ölçütlere sahip olduğu söylenebilir. Davis (1992) tekniğinde ise dörtlü derecelendirme olarak 1)"maddenin uyarlamas1 uygun", 2)"maddenin uyarlamas1 uygun fakat biraz düzeltme gerekli", 2)"maddenin uyarlamas uygun fakat ciddi düzeltme gerekli" 4) "maddenin uyarlaması uygun değil" derecelendirme ifadeleri kullanılmakta, kapsam geçerlik indeksi (a) ve (b) seçeneğini işaretleyen uzmanların sayısı toplam uzman sayısına bölünerek hesaplanmaktadır. Maddelere ait dil kapsam geçerlik indeks değerleri 0.89 ile 1.00 arasında değişmektedir. Davis'e (1992) göre kapsam geçerlik indeks değerlerinin .80'den büyük olması gerekmektedir. Dolayısıyla SMKBÖ'nün dil kapsam geçerlik indekslerinin yeterli olduğu söylenebilir.

\section{Yapı geçerliği}

Açımlayıcı faktör analizi (AFA)

İlk gruptan elde edilen verilere uygulanan AFA sonucu Bartlet Küresellik Testi değerinin $\chi^{2}=450.74$ $\mathrm{sd}=36(\mathrm{p}=.000)$ ve KMO örneklem uygunluk katsayısının .84 olduğu tespit edilmiştir. Mulaik'e (2010) göre bu sayının .60'tan büyük olması gerekmektedir. Hutcheson ve Sofroniou'ya (1999) göre ise KMO değerlerinin 0.80 ile 0.90 arasında olması ve Bartlet Küresellik Testi değerinin anlamlı olması örneklemin uygulama için elverişli olduğunu göstermektedir. Ayrıca ölçeğin orijinal yapısıyla uygun olarak dokuz maddenin tek faktörlü yapısı, ölçeğin toplam varyansının \%48.11'ini açıklamaktadır. AFA sonucu madde faktör yük değerleri .28 ile .81 arasında sıralanmaktadır (Bkz Tablo 1).

Tablo 1. AFA Sonucu Madde Faktör Yükleri 
Sarıçam, H., Adam Karduz, F. F. / Sosyal Medya Kullanım Bozukluğu Ölçeğinin Türk Kültürüne Uyarlanması: Geçerlik ve Güvenirlik Çalışması

\begin{tabular}{cccc}
\hline Madde No & $\begin{array}{c}\text { Madde faktör } \\
\text { yükleri }\end{array}$ & Madde No & $\begin{array}{c}\text { Madde faktör } \\
\text { yükleri }\end{array}$ \\
\hline $\mathbf{m 1}$ & .77 & $\mathbf{m 6}$ & .28 \\
$\mathbf{m} 2$ & .60 & $\mathbf{m 7}$ & .58 \\
$\mathbf{m 3}$ & .77 & $\mathbf{m 8}$ & .75 \\
$\mathbf{m 4}$ & .81 & $\mathbf{m 9}$ & .33 \\
$\mathbf{m 5}$ & .61 & & \\
\hline \multicolumn{4}{l}{ Toplam varyans oran1=48.11\% } \\
\hline
\end{tabular}

\section{Doğrulayıcı faktör analizi (DFA)}

AFA sonucu oluşan yapının doğrulanması için ikinci gruptan elde edilen verilere uygulanan DFA sonucu uyum indeksi değerleri $\chi^{2}=50.65, \mathrm{sd}=27\left(\chi^{2} / \mathrm{sd}=1.87\right), \mathrm{RMSEA}=.066, \mathrm{CFI}=.98, \mathrm{GFI}=.98$, $\mathrm{IFI}=.98, \mathrm{NFI}=.96, \mathrm{RFI}=.97$ ve $\mathrm{SRMR}=.039$ olarak bulunmuştur (Bkz. Şekil 1).

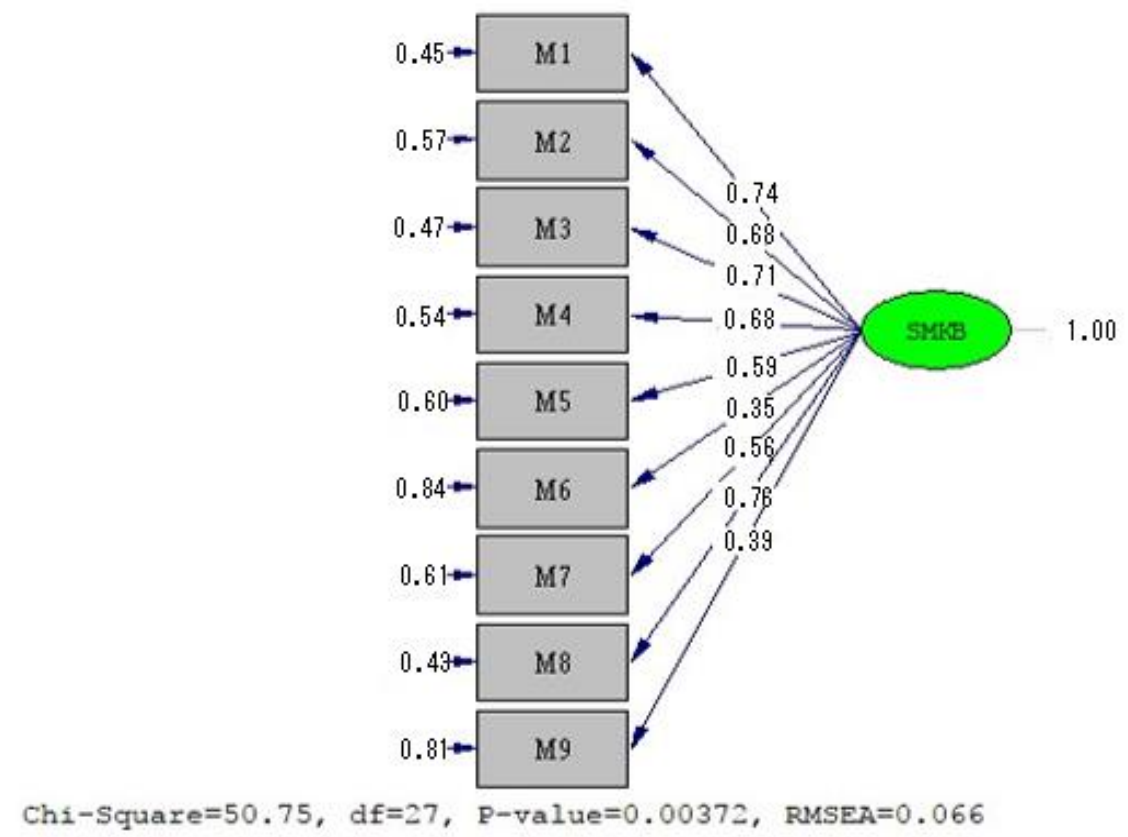

Şekil 1. DFA Madde Faktör Yük Değerleri

Şekil 1'de görüldüğü üzere farklı örneklem gruplarında ölçeğin yapısının test edildiği, tek boyuttan ve dokuz maddeden oluşan yapısının DFA sonucu madde faktör yük değerleri $(\lambda)$.35 ile .76 arasındadır.

\section{Ölçüt bağıntılı geçerlik}

Ölçeğin ölçüt bağıntılı geçerlik çalışmasında YIBT-KF ve EATBÖ-KF ile ilişki düzeyleri SpearmanBrown korelasyon testiyle incelenmiştir. SMKBÖ-9 ile YIBT-KF ve EATBÖ-KF arasında $\mathrm{p}<.01$ önem düzeyinde sırasıyla $r_{s}=.64, .66$ pozitif ilişkiler bulunmuştur (Bkz. Tablo 2). 
Tablo 2. Ölçme Araçlarının Ortalama, Standart Sapma, Cronbach Alfa ve İlgileşim Değerleri

\begin{tabular}{lccc}
\hline Ölçme araçları & 1. SMKBÖ & 2. YİBT-KF & 3. EATBÖ-KF \\
\hline 1. SMKBÖ-9 & - & $.64^{* *}$ & $.66^{* *}$ \\
2. YİBT-KF & & - & $.65^{* *}$ \\
3. EATBÖ-KF & & & - \\
Ortalama & 28.29 & 25.02 & 20.32 \\
Standart sapma & 19.29 & 10.60 & 9.93 \\
Cronbach alfa & .76 & .81 & .79
\end{tabular}

p*.01 SMKBÖ-9=Sosyal Medya Kullanım Bozukluğu Ölçeği, YİBT-KF=Young İnternet Bağımlılık Testi-Kısa Formu, EATBÖ-KF= Ergenler için Akıllı Telefon Bağımlılık Ölçeği-Kısa Formu

\section{Ayırt edici geçerlik}

Ölçeğin geçerliğini sınamak için yapılan bir diğer çalışmada ölçeğin ayırt ediciliği incelenmiştir. Ayırt edicilik analizlerinden yararlanılırken önceki analizde sosyal medya kullanım bozukluğunun, internet bağımlılığı ve akıllı telefon bağımlılığı ile yüksek düzeyde ilişkili olmasından dolayı SMKBÖ’nün, internet bağımlılığı ve akıllı telefon bağımlılığı bağlamında ayırt ediciliğinin incelenmesine karar verilmiştir. Bunun için internet bağımlısı olan ve olmayan; akıllı telefon bağımlısı olan ve olmayan iki ayrı veri seti oluşturulmuştur. Veri setleri oluşturulurken ölçeklerden elde edilebilecek en yüksek ve en düşük puanlardan \%33'lük dilimler ölçüt alınmıştır. İnternet bağımlılığı için 28 puan ve aşağısına "bağımlı değil", 44 puan ve yukarısına "bağımlı" denilmiştir. Akıllı telefon bağımlığ için 23 puan ve altı "bağımlı değil", 37 ve yukarısı "bağımlı" olarak gruplar oluşturulmuştur. Diskriminant analizi için belirlenen bu grupların SMKBÖ' den aldıkları puanları açısından Wilks' Lambda istatistiğiyle Kanonik (Cannonical) Diskriminant Fonksiyonları değerlendirilmiştir. Elde edilen bulgular Tablo 3 ve 4 'te gösterilmiştir.

Tablo 3. Young İnternet Bağımlılık Testi-Kısa Formunun Gruplarına Göre SMKBÖ Wilks’ Lambda İstatistiği

\begin{tabular}{ccccccc}
\hline Fonksiyon & Wilks' Lambda & $\mathrm{F}$ & Ki-kare & $\mathrm{sd}$ & $\mathrm{p}$ & Kanonik korelasyon \\
\hline 1 & .60 & $66.69^{* *}$ & 102.301 & 2 & .000 & .63 \\
${ }^{* * *} \mathrm{p}<.01$ & & & & & &
\end{tabular}

Tablo 4. Ergenler İçin Akıllı Telefon Bağımlılık Ölçeğini Gruplarına Göre SMKBÖ Wilks’ Lambda İstatistiği

\begin{tabular}{ccccccc}
\hline Fonksiyon & Wilks' Lambda & $\mathrm{F}$ & Ki-kare & $\mathrm{sd}$ & $\mathrm{p}$ & Kanonik korelasyon \\
\hline 1 & .50 & $98.45^{* *}$ & 137.265 & 2 & .000 & .70 \\
\hline${ }^{* *} \mathrm{p}<.01$ & & & & & & \\
& & & & & &
\end{tabular}

Tablo 3'te verilen YIBBT-KF fonksiyonun Wilks'Lambda istatistiğine ilişkin ki-kare değeri $\left[\chi_{(2)}^{2}=\right.$ $102.301 ; \mathrm{p}<.01]$ ve Wilks' Lambda değeri $(\lambda) .60$ istatistiksel olarak anlamlı bulunmuştur. Ayrıca kanonik küme korelasyon katsayıları incelendiğinde (.63), internet bağımlılığı sosyal medya kullanım bozukluğu için paylașılan varyansın \%40'ını açıklamaktadır. Tablo 4'de verilen EATBÖKF fonksiyonun Wilks' Lambda istatistiğine ilişkin ki-kare değeri $\left[\chi_{(2)}^{2}=137.265 ; p<.01\right]$ ve Wilks' Lambda değeri $(\lambda) .50$ istatistiksel olarak anlamlı bulunmuştur. Bununla birlikte kanonik küme korelasyon katsayıları incelendiğinde (.70), akıllı telefon bağımlılığı sosyal medya kullanım bozukluğu için paylaşılan varyansın \%49'unu açıklamaktadır.

\section{Güvenirlik}


Ölçeğin güvenirlik çalışmaları üçüncü gruptan elde edilen verilerle yapılmıştır. Cronbach alfa iç tutarlık güvenirlik katsayısı $\alpha=.76$ olarak hesaplanmıştır. Yarıya bölme analiz bulgularında ise Spearman-Brown iki yarı arasındaki korelasyon katsayıs1 $r=.47$, Guttman split-half katsayıs1 .64 , her iki yarı için Cronbach $\alpha$ değerleri, ilk yarı için (5 soru) $\alpha=.69$, ikinci yarı için (5 soru) $\alpha=.51$ olarak bulunmuştur. Alanyazında Cronbach $\alpha$ değerinin minimum olarak .70 olması gerektiği (Cortina,1993; Cronbach, 1951), fakat ölçek çok spesifik veya sınırlı bir özelliği ölçüyorsa .70'ten düşük bir değer alabileceği belirtilmiştir (Kline,1979, s., 292).

\section{Madde analizleri}

SMKBÖ'nin madde analiz sonuçlarına göre düzeltilmiş madde toplam korelasyon değerleri .29 ile .73 arasında sıralanmaktadır. Alanyazında düzeltilmiş madde toplam korelasyon değerleri ile ilgili ölçüt ilgili değerlerin .30'dan büyük olmasıdır (Kline, 2000:523). Altıncı madde hariç diğer tüm bu maddeler için ölçütün sağlandığı görülmektedir. Ayrıca her bir maddenin alt-üst \%27 madde ayırt edicilik indeks değerleri incelenmiş ve $\mathrm{t}$ değerlerinin $\mathrm{p}<01$ önem düzeyinde 3.92 ile 19.51 arasında değiştiği gözlenmiştir (Bkz Tablo 5).

Tablo 5. Madde Toplam İlgileşim ve Madde Ayırt Edicilik İndeks Değerleri

\begin{tabular}{lccc}
\hline Madde No & $\mathrm{R}_{\mathrm{jx}}$ & $\begin{array}{c}\text { Eğer madde silinirse } \\
\text { Cronbach alfa değerleri }\end{array}$ & $\begin{array}{c}\text { Alt-üst \%27 } \\
\text { madde ayırt edicilik } \\
\text { indeksi (t) }\end{array}$ \\
\hline m1-meşguliyet & .670 & .537 & $13.70^{* *}$ \\
m2-dayanma & .649 & .564 & $13.97^{* *}$ \\
m3-yoksunluk & .663 & .546 & $14.96^{* *}$ \\
m4-Israr & .561 & .542 & $13.17^{* *}$ \\
m5-kaçış & .476 & .661 & $11.66^{* *}$ \\
m6-problem & .288 & .766 & $3.92^{* *}$ \\
m7-aldatma & .474 & .636 & $7.07^{* *}$ \\
m8-yer değiştirme & .726 & .534 & $19.51^{* *}$ \\
m9-çatışma & .321 & .762 & $4.39^{* *}$ \\
\hline **p<.01 & & &
\end{tabular}

\section{TARTIŞMA ve SONUÇLAR}

Sosyal Medya Kullanım Bozukluğu Ölçeği'nin ergenler üzerinde psikometrik özelliklerini incelemenin amaçlandığı bu çalışmada ölçeğin geçerlik, güvenirlik değerleri ile madde analizleri sınanmıştır. İlk olarak dil kapsam geçerliği iki ayrı teknikle değerlendirilmiştir. Her bir maddenin Türkçe ve İngilizceleri için 9 uzmandan alınan değerlerle hesaplanan dil kapsam geçerlik indeks değerleri alanda ölçüt kabul edilen .75 (Veneziano \& Hooper, 1997) ve .80'den (David, 1992) büyüktür. Dolayısıyla ölçeğin dil kapsam geçerliğinin sağlandığı söylenebilir. Yapı geçerliği için iki farklı veri setine AFA ve DFA yapılmıştır. AFA sonucunda KMO değeri 0.80-0.90 arası olduğu için bu veri grubu için örneklem sayısının faktör analizine uygun olduğu söylenebilir (Kaiser, 1974). Ayrıca Bartlett küresellik testinin manidarlık değeri .05 alfa değerinden küçük olduğu için yokluk hipotezi ret edilir. Bu durumda korelasyon matrisi birim matris olmayıp faktör analizi için uygundur (Dziuban \& Shirkey, 1974). Bununla birlikte ölçeğin AFA sonucunda maddelerin faktör yük değerleri (6. madde hariç) alanyazında ölçüt kabul edilen .30 (Stevens, 2002) ya da .32 'den (Tabacnick \& Fidell, 2014) büyüktür. Böyle bir durumda madde 6'nın atılması gereklidir, fakat bu madde bağımlılık kriterlerinden birine ait olduğundan ve ölçek bütünlüğü bozulacağından uzman görüşlerine dayanarak maddenin atılmaması kararlaştırılmıştır (Tekeş \& Hasta, 2015). Madde 6'nın faktör yükünün düşük çıkması örneklem büyüklüğünün yetersiz olmasından kaynaklanabilir 
(MacCallum, Widaman, Zhang \& Hong, 1998; Velicer \& Fava, 1998). Ölçeğin orijinalindeki yapının Türk ergenlerde doğrulanıp doğrulanmadığını belirlemek için DFA sonucu uyum indeksi değerlerinden $\chi 2 / \mathrm{sd}, \mathrm{CFI}, \mathrm{GFI}$, IFI, NFI, RFI, SRMR değerleri alanyazında belirtilen ölçütlere $\left(\chi^{2} / \mathrm{sd}<2, \mathrm{CFI}>.95, \mathrm{GFI}>.95, \mathrm{IFI}>.95, \mathrm{NFI}>.95, \mathrm{RFI}>.95, \mathrm{SRMR}<.05\right)$ göre iyi özellik gösterirken; RMSEA değeri (RMSEA<.08) kabul edilebilir düzeydedir (Barrett, 2007; Erkorkmaz vd., 2013; Harrington, 2009; Kline, 2011; Schermelleh-Engel, Moosbrugger, \& Müller, 2003; Vieira, 2011). Ölçüt bağıntılı geçerlik çalışmasında SMKBÖ’nin YIBBT-KF ve EATBÖ-KF ile $p<.01$ önem düzeyinde .60 ile .70 arasında ilişki katsayılarına sahip olması alanyazında yüksek düzeyde ilişki (Alper, 2006) olarak adlandırıldığından eşdeğer ölçek geçerliliğinin sağlandığı söylenebilir.

Ölçeğin ayırt edici geçerlik çalışmasında Wilks' Lambda değeri $\mathrm{p}<.01$ önem düzeyinde manidar olduğundan (Ceyhan, Ceyhan, \& Gürcan, 2007; Garson, 2012) SMKBÖ’nün internet bağımlılı̆̆ı ve akıllı telefon bağımlılı̆̆ına göre oluşturulmuş grupları ayırt edicilik etkisinin yüksek olduğu söylenebilir. Bir başka ifade ile ölçek sosyal medya kullanım bozukluğu olanlar ile olmayanları, internet ve akıllı telefon bağımlılığı olanlar ile olmayanları ayırt edebilmektedir. Çalışmanın bu bulgusu "bir madde, cisim, nesne ya da şeye bağımlılık beraberinde birçok bağımlılık türünü ortaya çıkarabileceği” gerçeğini teknolojik yakınsama bağlamında gözler önüne sermiştir. Bir başka ifadeyle sosyal medya kullanım bozukluğu beraberinde internet bağımlılığı ve akıllı telefon bağımlılığını da tetiklemektedir (Kırcaburun, 2016; Saied, Elsabagh \& El-Afandy, 2016; Sali, 2013; Şimşek \& Balaban Sali, 2014; Veronica \& Samuel, 2015).

Ölçeğin güvenirlik analizlerinde Cronbach alfa iç tutarlık güvenirlik katsayısının .70’ten büyük (Nunnally, 1974; Özdamar, 2002; Şencan, 2005; Tavşanc11, 2014; Traub, 1994) olması iç tutarlık güvenirliğinin psikolojik testlerde kabul edilebilir olduğunu göstermektedir. İki yarı test bulgularında Spearman-Brown, Guttman split-half ve Cronbach $\alpha$ katsayılarının alanyazında ölçüt kabul edilen .30 ile .70 arasında olmasının (Soğuksu ve Alıcı, 2016) kabul edilebilir fakat çok düşük değerler olduğu söylenebilir. Alanyazında kişilik ve kişilik bozukluğu gibi çok özel yapıları değerlendiren ölçeklerde Cronbach $\alpha$ katsayısının .43 ile .70 arasında değiştiği çalışmalar da bulunmaktadır (Cattell, 2007; Cattell \& Schuerger, 2003; Cattell, Eber, \& Tatsuoka, 1970; Grygier \& Grygier, 1976; Soyer, Rovenpor, Kopelman, Mullins, \& Watson, 2001). Patolojik internet kullanımının kişilik bozukluklarında önemli bir gösterge olduğunu aktaran çalışmalar (Muller, Beutel, Egloff, \& Wolfling, 2014; Muller, Koch, Dickenhorst, Beutel, Duven, E., \& Wolfling 2013) 1şı̆ğında sosyal medya kullanım bozukluğunun spesifik bir kavram olduğu söylenebilir.

Madde analizlerinde düzeltilmiş madde toplam korelasyonlarının (madde 6 hariç) alanyazında ölçüt olarak bilinen .30'dan yüksek (Kline, 2000) olması her bir maddenin ölçeğin bütünü ile yeteri şekilde tutarlı olduğunu göstermektedir. Madde 6 için bu değerin .29 olması bir sinırlılık arz etse de ölçütün .30'dan küçük tutulduğu çalışmalar da mevcuttur (Acat, Tüken, \& Karadağ, 2010; Tuğut \& Gölbaşı, 2010). Ayrıca her bir maddenin alt-üst $\% 27$ madde ayırt edicilik indeks değerlerinin ( $t$ ) p $<.01$ önem düzeyinde manidar olmas1 (Brennan, 1972) maddelerin ayırt edicilik gücünün yüksek olduğunu göstermektedir. Diğer taraftan Van den Eijnden, Lemmens ve Valkenburg (2016) tarafindan geliştirilen ölçeğin orijinal formu ile Türkçe sürümünün psikometrik özelliklerinde farklılaşmalar vardır; orijinal formun geçerlik ve güvenirlik değerlerinin daha yüksek olduğu söylenebilir. Bunun sebebinin ise kültürel farklılıklar (Korkmaz, 2007), kullanılan psikolojik terimlerin yanlış karşıllı̆ı (Erkuş, 2000; 2010), sosyal medyanın kullanım süresi ve amaçlarının farklılaşmasından kaynaklandığı söylenebilir. Bağımlılık terimi çok hassas bir psikolojik kavram olduğundan, bu kavramı içeren ifadelerin kullanımında da hassas olmak gerekir, çünkü psikolojik kavramlar kültüre duyarlıdır (Gözüm ve Aksayan, 2003; Hambleton, Merenda, \& Spielberger, 2005). Dolayısıyla bir ölçeğin farklı kültürlerde geçerlik ve güvenirlik değerlerinin farklı olması olağan bir durumdur.

Sonuç olarak ölçeğin dil kapsam geçerliği, yapı geçerliği, ölçüt geçerliği, ayırt edici geçerlik ve güvenirlik değerlerine dayanarak Sosyal Medya Kullanım Bozukluğu Ölçeği'nin ergenlerin sosyal medya bağımlılığını ölçme ve değerlendirmede kullanmada geçerli ve güvenilir bir ölçme aracı olduğu söylenebilir. Bununla birlikte ölçeğin geçerlik ve güvenirlik değerlerine güç katmak amaciyla aşağıdaki öneriler yapılabilir: 
- İki yarıdaki maddelerin homojen olarak aynı şeyi ölçmediği görülmektedir. Bu ifade olumsuzmuş gibi anlaşılsa da ölçeğin orijinal yapısı düşünüldügünde mantıklı gelmektedir, çünkü ölçek maddeleri toplam bir puan verse de aslında her bir madde farklı ölçütleri değerlendirmek için hazırlanmıştır. Bundan dolayı eşdeğer yarılar güvenirliğinin Spearman-Brown formülüyle ile hesaplanması yerine Flanagan formülüyle hesaplanması iki yarı testlere ilişkin varyansları birbirine yaklaştıracak ve yarı testler arasındaki korelasyon katsayısını arttıracaktır.

- Ölçeğin test-tekrar-test güvenirlik analizleri, ilk uygulama ile ikinci uygulama arasına son sınavlar ve yaz tatili girdiğinden dolayı yapılamamıştır. Farklı çalışmalar ile bu çalışmanın test tekrar test güvenirlik katsayıları hesaplanabilir. Özellikle çalışmanın farklı illerde, farklı liselerde ergen grupları ile genişletilmesi ölçeğin genellebilirliği açısından önemli katkılar sağlayacaktır.

\section{KAYNAKÇA}

Aboujaoude, E. (2010). Problematic internet use: An overview. World Psychiatry, 9(2), 85-90.

Acat, M. B., Tüken, G. \& Karadağ, E. (2010). Bilimsel Epistemolojik İnançlar Ölçeği: Türk kültürüne uyarlama, dil geçerliği ve faktör yapısının incelenmesi. Türk Fen Eğitim Dergisi, 7(4), 67-89.

Aftab, R., Çelik, İ., \& Sarıçam, H. (2015). Facebook addiction and social emotional learning skills. Ozean Journal of Social Science, 8(2), 109-120. doi: 10.13140/RG.2.2.21774.66887

Ahn, J. (2011). The effect of social network sites on adolescents' social and academic development: Current theories and controversies. Journal of the American Society for Information Science and Technology, 8(62), 1435-1445. doi: 10.1002/asi.21540

Akın, A., Altundağ, Y., Turan, M. E., \& Akın, U. (2014). The validity and reliability of the Turkish version of the Smart Phone Addiction Scale-Short Form for Adolescent. Procedia-Social and Behavioral Sciences, 152, 74-77. doi: 10.1016/j.sbspro.2014.09.157

Alper, R. (2006). Spor bilimlerinde uygulamalı istatistik. Ankara: Nobel Akademik.

Ang, C. S., Chan, N. N., \& Lee, C. S. (2017). Shyness, loneliness avoidance, and internet addiction: What are the relationships? The Journal of Psychology, 13, 1-11. doi: 10.1080/00223980.2017.1399854

Andreassen, C. S. (2015). Online social network site addiction: A comprehensive review. Current Addiction Reports, 2(2), 175-184. doi: 10.1007/s40429-015-0056-9

Andreassen, C. S., Pallesen, S., \& Griffiths, M. D. (2017). The relationship between addictive use of social media, narcissism, and self-esteem: Findings from a large national survey. Addictive Behaviors, 64, 287-293. doi: 10.1016/j.addbeh.2016.03.006

American Psychiatric Association. (2013). Diagnostic and statistical manual of mental disorders (5th ed.). Washington, DC: American Psychiatric Association.

Appel, H., Crusius, J., \& Gerlach, A. L. (2015). Social comparison, envy, and depression on Facebook: A study looking at the effects of high comparison standards on depressed individuals. Journal of Social and Clinical Psychology, 34(4), 277-289. doi: 10.1521/jscp.2015.34.4.277.

Barrett, P. (2007). Structural equation modelling: Adjudging model fit. Personality and Individual Differences, 42(5), 815-24. doi:10.1016/j.paid.2006.09.018

Best, P., Manktelow, R., \& Taylor, B. (2014). Online communication, social media and adolescent wellbeing: A systematic narrative review. Children and Youth Services Review, 41, 27-36. doi: 10.1016/j.childyouth.2014.03.001

Blackwell, D., Leaman, C., Tramposch, R., Osborne, C., \& Liss, M. (2017). Extraversion, neuroticism, attachment style and fear of missing out as predictors of social media use and addiction. Personality and Individual Differences, 116, 69-72. doi: 10.1016/j.paid.2017.04.039

Bland, J., \& Altman, D. (1997). Statistics notes: Cronbach's alpha. BMJ, 314, 572. doi: 10.1136/bmj.314.7080.572

Brennan, R. (1972). A generalized upper-lower item discrimination index. Educational and Psychological Measurement, 32(2), 289-303. doi: 10.1177/001316447203200206

Byun, S., Ruffini, C., Mills, J. E., Douglas, A. C., Niang, M., Stepchenkova., S. .. Blanton, M. (2009). Internet addiction: Metasynthesis of 1996-2006 quantitative research. CyberPsychology \& Behavior, 12(2), 203-207. doi: $10.1089 / \mathrm{cpb} .2008 .0102$.

Cabral, J. (2011). Is generation Y addicted to social media. The Elon Journal of Undergraduate Research in Communications, 2(1), 1-10.

Cattell, H. E. P. (2007). Exploring your 16PF profile. Oxford: Oxford Psychologist Press.

Cattell, H. E. P., \& Schuerger, J. M. (2003). Essentials of the 16PF assessment. New York: John Wiley \& Sons. 
Cattell, R. B., Eber, H. W., \& Tatsuoka, M. M. (1970). Handbook for the Sixteen Personality Factor Questionnaire (16PF). Institute for Personality and Ability Testing, Champaign, Ill.

Caumont, A. (2014). Americans increasingly view the internet, cellphones as essential. Retrieved from http://www.pewresearch.org/fact-tank/2014/02/27/americans-increasingly-view-the-internetcellphones-as-essential/

Ceyhan, E., Ceyhan, A. A. \& Gürcan, A. (2007). Problemli İnternet Kullanımı Ölçeği’nin geçerlik çalışmaları. Kuram ve Uygulamada Ĕgitim Bilimleri, 7(1), 387-416.

Chaffey, D. (2017). Global social media research summary 2017. [Online] Retrieved from http://www.smartinsights.com/social-media-marketing/social-media-strategy/new-global-social-mediaresearch/ [Accessed 1 May 2017].

Charter, R. A. (2001). It's time to bury the Spearman-Brown "prophecy" formula for some common applications. Educational and Psychological Measurement, 61(4), 690-696.

Chiou, W.-B., Lee, C.-C., \& Liao, D.-C. (2015). Facebook effects on social distress: Priming with online social networking thoughts can alter the perceived distress due to social exclusion. Computers in Human Behavior, 49, 230-236. doi:10.1016/j.chb.2015.02.064

Collier, R. (2009). Internet addiction: New-age diagnosis or symptom of age-old problem? CMAJ: Canadian Medical Association Journal, 181(9), 575-576. doi: 10.1503/cmaj.109-3052

Cortina, J. M. (1993). What is coefficient alpha? An examination of theory and applications. The Journal of Applied Psychology, 78(1), 98-104. doi:10.1037/0021-9010.78.1.98

Cronbach, L. J. (1951). Coefficient alpha and the internal structure of tests. Psychometrika, 16(3), 297-334. doi:10.1007/BF02310555

Çokluk, Ö., Şekercioğlu, G., \& Büyüköztürk, Ş. (2010). Sosyal bilimler için çok değişkenli istatistik. SPSS ve Lisrel uygulamall. Ankara: Pegem Akademi.

Davila, J., Hershenberg, R., Feinstein, B. A., Gorman, K., Bhatia, V., \& Starr, L. R. (2012). Frequency and quality of social networking among young adults: Associations with depressive symptoms, rumination, and corumination. Psychology of Popular Media Culture, 1(2), 72-86. doi: 10.1037/a0027512.

Davis, L. L. (1992). Instrument review: Getting the most from a panel of experts. Applied Nursing Research, 5(4), 194-197. doi: 10.1016/S0897-1897(05)80008-4.

Dobrean, A., \& Păsărelu, C. R. (2016). Impact of social media on social anxiety: A systematic review. In Federico Durbano (Ed.), New Developments in Anxiety Disorders (pp.129-149). doi: 10.5772/65188. Retrieved from https://www.intechopen.com/books/new-developments-in-anxiety-disorders/impact-ofsocial-media-on-social-anxiety-a-systematic-review

Douglas, A. C., Mills, J. E., Niang, M., Stepchenkova, S., Byun, S., Ruffini, C. ... Blanton, M. (2008). Internet addiction: Meta-synthesis of qualitative research for the decade 1996-2006. Computers in Human Behavior, 24(6), 3027-3044. doi:10.1016/j.chb.2008.05.009

Dumitrache, S. D., Mitrofan, L., \& Petrov, Z. (2012). Self-image and depressive tendencies among adolescent Facebook users. Revista de Psihologie, 58(4), 285-295.

Dziuban, C. D., \& Shirkey, E. C. (1974). When is a correletion matrix appropriate for factor analysis? Some decision rules. Psychological Bulletin, 81(6), 358-361.

Ekşi, H. \& Çiftçi, M. (2017). Lise öğrencilerinin problemli internet kullanım durumlarının dinî inanç ve ahlaki olgunluk düzeylerine göre yordanması. Addicta: The Turkish Journal on Addictions, 4, 181-206. doi:10.15805/addicta.2017.4.2.0013

Erfanmanesh, M., \& Hosseini, E. (2015). [Review of the book Internet and Social Media Addiction by Nakaya, $\begin{array}{lllll}\text { Andrea } & \text { C.]. } & \text { Webology, } & \text { Retrieved } & \text { from }\end{array}$ http://www.webology.org/2015/v12n2/bookreview25.pdf

Erkorkmaz, Ü., Etikan, İ., Demir, O., Özdamar, K. \& Sanisoğlu, S. Y. (2013). Doğrulayıcı faktör analizi ve uyum indeksleri. Turkiye Klinikleri Journal of Medical Sciences, 33(1), 210-223. doi: 10.5336/medsci.2011-26747

Erkuş, A. (2000). Bazı psikometrik terimlerin Türkçe karşılıklarında yaşanan sorunlar. Türk Psikoloji Yazıları, $3(6), 31-40$.

Erkuş A. (2010). Psikometrik terimlerin Türkçe karşılıklarının anlamları ile yapılan işlemlerin uyuşmazlığı. Ĕ̈itimde ve Psikolojide Ölçme ve Değerlendirme Dergisi,1(2),72-77.

Esen, E., \& Siyez, D. M. (2011). An investigation of psycho-social variables in predicting internet addiction among adolescents. Turkish Psychological Counseling \& Guidance Journal, 36, 127-138.

Frost, R. L., \& Rickwood, D. J. (2017). A systematic review of the mental health outcomes associated with Facebook use. Computers in Human Behavior, 76, 576-600. doi: 10.1016/j.chb.2017.08.001

Garson, G. D. (2012). Discriminant function analysis. Asheboro, NC: Statistical Associates Publishers.

Gözüm, S. \& Aksayan, S. (2003). Kültürlerarası ölçek uyarlaması için rehber II: Psikometrik özellikler ve kültürlerarası karşılaştırma. Hemşirelikte Araştırma Geliştirme Dergisi, 1, 3-14. 
Griffiths, M. (2005). A 'components' model of addiction within a biopsychosocial framework. Journal of Substance Use, 10(4), 191-197. doi: 10.1080/14659890500114359

Griffiths, M. D. (2010). The role of context in online gaming excess and addiction: Some case study evidence. International Journal of Mental Health and Addiction, 8(1), 119-125.

Griffiths, M. D. (2013). Social Networking Addiction: Emerging themes and issues. Journal of Addiction Research \& Therapy, 4(5), e188. doi: 10.4172/2155-6105.1000e118

Griffiths, M., Van Rooij, A. J., Kardefelt-Winther, D., Starcevic, V., Kiraly, O., Pallesen, S. ... Demetrovics, Z. (2016). Working towards an international consensus on criteria for assessing Internet Gaming Disorder: A critical commentary on Petry, et al (2014). Addiction, 111(1), 167-175. doi:10.1111/add.13057

Griffiths, M. D., Kuss, D. J., \& Demetrovics, Z. (2014). Social networking addiction: An overview of preliminary findings. In Behavioral addictions. Criteria, evidence, and treatment (pp. 119-141). New York: Elsevier.

Grygier, J. G., \& Grygier, P. (1976). Dynamic Personality Inventory. Montreal: Institute of Psychological Research.

Günlü, A. \& Ceyhan, A. A. (2017). Ergenlerde internet ve problemli internet kullanım davranışının incelenmesi. Addicta: The Turkish Journal on Addictions, 4(1), 75-117. http://dx.doi.org/10.15805/addicta.2017.4.1.0016

Hambleton, R. K., Merenda, P. F., \& Spielberger, C. D. (2005). Adapting educational and psychological tests for cross-cultural assessment. New Jersey: Lawrence Erlbaum Associations.

Harrington, D. (2009). Assessing confirmatory factor analysis model fit and model revision. Confirmatory factor analysis. New York: Oxford University Press.

Hawi, N. S., \& Samaha, M. (2016). The relations among social media addiction, self-esteem, and life satisfaction in university students. Social Science Computer Review, 35(5), 576-586 doi: $10.1177 / 0894439316660340$

Hur, M. H. (2006). Demographic, habitual, and socioeconomic determinants of internet addiction disorder: An empirical study of Korean teenagers. CyberPsychology \& Behavior, 9(5), 514-525. doi: 10.1089/cpb.2006.9.514

Hutcheson, G., \& Sofroniou, N. (1999). The multivariate social scientist: Introductory statistics using generalized linear models. Thousand Oaks, CA: Sage Publications.

Islam, A., \& Hossin, M. Z. (2014). Prevalence and risk factors of problematic internet use and the associated psychological distress among graduate students of Bangladesh. Asian Journal of Gambling Issues and Public Health, 6(1), 11. doi:10.1186/s40405-016-0020-1

Kaiser, H. F. (1974). An index of factorial simplicity. Psychometrika, 39, 31-36.

Kempa, E. P. (2015). Social media addiction-The paradox of visibility \& vulnerability. (Master's thesis). Retrieved from http://urn.kb.se/resolve?urn=urn:nbn:se:hb:diva-1030

Khan, S. F., Ullah, F., Khan, M. K., Raza, A. J. S., \& Shah, H. (2017). Effect of social media addiction on compliance in the patients of District Bannu, Khyber PakhtunKhwa. International Journal of Basic Medical Sciences and Pharmacy (IJBMSP), 6(2), 21-25.

Kircaburun, K. (2016). Self-esteem, daily internet use and social media addiction as predictors of depression among Turkish adolescents. Journal of Education and Practice, 7(24), 64-72.

Kırık, A. M., Arslan, A., Çetinkaya, A., \& Gül, M. (2015). A quantitative research on the level of social media addiction among young people in Turkey. International Journal of Science Culture and Sport (IntJSCS), 3(3), 108-122.

Kline, R. B. (2011). Principles and practice of Structural Equation Modeling. New York: The Guilford Press.

Kline, P. (2000). Handbook of psychological testing (2nd Ed.). London: Routledge.

Kline, P. (1979). Psychometrics and psychology. London, United Kingdom: Academic Press.

Koçer, M. (2012). Erciyes Üniversitesi öğrencilerinin internet ve sosyal medya kullanım alışkanlıkları. Akdeniz Iletişim, 18, 70-85.

Korkmaz, M. (2007). Psikolojik ölçmenin yeni kuralları ve Türkiye'deki durumu. Türk Psikoloji Bülteni, 13(40), 8-14.

Kormas, G., Critselis, E., Janikian, M., Kafetzis, D., \& Tsitsika, A. (2011). Risk factors and psychosocial characteristics of potential problematic and problematic internet use among adolescents: A crosssectional study. BMC Public Health, 11, 595. doi: 10.1186/1471-2458-11-595

Kozeis, N. (2009). Impact of computer use on children's vision. Hippokratia, 13(4), 230-231.

Kuss, D. J., \& Griffiths, M. D. (2011). Online social networking and addiction-A review of the psychological literature. International Journal of Environmental Research and Public Health, 8(9), 3528-3552. doi: 10.3390/ijerph8093528 
Kutlu, M., Savc1, M., Demir, Y. \& Aysan, F. (2016). Young İnternet Bağımlılı̆̆ı Testi Kısa Formunun Türkçe uyarlaması: Üniversite öğrencileri ve ergenlerde geçerlilik ve güvenilirlik çalışması. Anatolian Journal of Psychiatry, 17(Suppl. 1), 69-76.

Kwon, M., Kim, D. J., Cho, H., \& Yang, S. (2013). The Smartphone Addiction: Development and validation of a short version for Adolescents (SAS-SV). PLOS ONE, 8(12), e83558. doi: 10.1371/journal.pone.0083558

Lawshe, C. H. (1975). A quantitative approach to content validity. Personnel Psychology, 28, 563-575. doi: 10.1111/j.1744-6570.1975.tb01393.x

Lemmens, J. S., Valkenburg, P. M., \& Gentile, D. A. (2015). The internet gaming disorder scale. Psychological Assessment, 72, 567-582. doi:10.1037/pas0000062

Lemmens, J. S., Valkenburg, P., \& Peter, J. (2009). Development and validation of a game addiction scale for adolescents. Media Psychology, 12, 77-95. doi:10.1080/15213260802669458.

Levenson, J. C., Shensa, A., Sidani, J. E., Colditz, J. B., \& Primack, B. A. (2016). The association between social media use and sleep disturbance among young adults. Preventive medicine, 85, 36-41. doi: 10.1016/j.ypmed.2016.01.001

Li, D., Zhang, W., Li, X., Zhou, Y., Zhao, L., \& Wang, Y. (2016). Stressful life events and adolescent internet addiction: The mediating role of psychological needs satisfaction and the moderating role of coping style. Computers in Human Behavior, 63, 408-415. doi:10.1016/j.chb.2016.05.070.

Lin, L. yi, Sidani, J. E., Shensa, A., Radovic, A., Miller, E., Colditz, J. B., ... Primack, B. A. (2016). Association between social media use and depression among U.S. young adults. Depression and Anxiety, 33(4), 323-331. doi:10.1002/da.22466

MacCallum, R. C., Widaman, K. F., Preacher, K. J., \& Hong, S. (2001). Sample size in factor analysis: The role of model error. Multivariate Behavioral Research, 36(4), 611-637. doi: 10.1207/S15327906MBR3604_06

Mahmood, S., \& Farooq, U. (2014). Facebook addiction: A study of big-five factors and academic performance amongst students of IUB. Global Journal of Management and Business Research, 14(5), 55-71.

Milani, L., Osualdella, D., \& Di Blasio, P. (2009). Quality of interpersonal relationships and problematic internet use in adolescence. CyberPsychology \& Behavior, 12, 681-684. doi:10.1089/cpb.2009.0071.

Morahan-Martin, J, \& Schumacher, P. (2000). Incidence and correlates of pathological internet use among college students. Computers in Human Behavior, 16(1), 13-29.

Moreno, M. A., Jelenchick, L. A., Egan, K. G., Cox, E., Young, H., Gannon, K. E., \& Becker, T. (2011). Feeling bad on Facebook: Depression disclosures by college students on a social networking site. Depress Anxiety, 28(6), 447-455. doi: 10.1002/da.20805.

Morin-Major, J. K., Marin, M-F., Durand, N., Wan, N., Juster, R-P., Lupien, S. J. (2016). Facebook behaviors associated with diurnal cortisol in adolescents: Is befriending stressful? Psychoneuroendocrinology, 63, 238-246. doi:10.1016/j.psyneuen.2015.10.005

Mulaik, S. A. (2010). The foundations of factor analysis (2nd ed.). Boca Raton, FL: Chapman \& Hall/CRC.

Muller, K. W., Beutel, M. E., Egloff, B., \& Wolfling, K. (2014). Investigating risk factors for internet gaming disorder: A comparison of patients with addictive gaming, pathological gamblers and healthy controls regarding the big five personality traits. European Addiction Research, 20(3), 129-136. doi: $10.1159 / 000355832$

Muller, K. W., Koch, A., Dickenhorst, U., Beutel, M. E., Duven, E., \& Wolfling K. (2013). Addressing the question of disorder-specific risk factors of internet addiction: A comparison of personality traits in patients with addictive behaviors and comorbid internet addiction. Biomed Research International, 2013, 1-7. doi:10.1155/2013/546342

Nabi, R. L., Prestin, A., \& So, J. (2013). Facebook friends with (health) benefits? Exploring social network site use and perceptions of social support, stress, and well-being. Cyberpsychology, Behavior, and Social Networking, 16(10), 721-727. doi: 10.1089/cyber.2012.0521

Nunnally, J. C. (1974). Psychometric theory (2nd ed.). New York: McGraw-Hill.

O'Keeffe, G. S., \& Clarke-Pearson, K. (2011). The impact of social media on children, adolescents, and families. Pediatrics, 127(4), 800-804. doi: 10.1542/peds.2011-0054

Otrar, M. \& Argın, F. S. (2014). Öğrencilerin sosyal medyaya ilişkin tutumlarının kullanım alışkanlıkları bağlamında incelenmesi. Journal of Research in Education and Teaching, 3(3), 1-13.

Otu, A. A. (2015). Social media addiction among students of the University of Ghana (Master dissertation). Retrieved from http://hdl.handle.net/123456789/21223

Owusu-Acheaw, M., \& Larson, A. G. (2015). Use of social media and its impact on academic performance of tertiary institution students: A study of students of Koforidua Polytechnic, Ghana. Journal of Education and Practice, 6(6), 94-101. Retrieved from http://files.eric.ed.gov/fulltext/EJ1083595.pdf 
Özdamar, K. (2013). Paket programlart ile istatiksel veri analizi cilt 2 (9. Bask1). Ankara: Nisan.

Özdamar, K. (2002). Paket programlarla istatistiksel veri analizi-1. Eskişehir: Kaan.

Pantic, I. (2014). Online social networking and mental health. Cyberpsychology, Behavior, and Social Networking, 17(10), 652-657. doi: 10.1089/cyber.2014.0070

Pawlikowski, M., Altstötter-Gleich, C., \& Brand, M. (2013). Validation and psychometric properties of a short version of Young's Internet Addiction Test. Computers in Human Behavior, 29(3), 1212-1223. doi: 10.1016/j.chb.2012.10.014

Robbins, T. W., Gillan, C. M., Smith, D. G., de Wit, S., \& Ersche, K. D. (2012). Neurocognitive endophenotypes of impulsivity and compulsivity: Towards dimensional psychiatry. Trends in Cognitive Sciences, 16(1), 81-91. doi: 10.1016/j.tics.2011.11.009.

Rosenfield, M. (2016). Computer vision syndrome (a.k.a. digital eye strain). Optometry in Practice, 17(1), 110.

Rus, H. M., \& Tiemensma, J. (2017). Social media under the skin: Facebook use after acute stress impairs cortisol recovery. Frontiers in Psychology, 8, 1609. doi: 10.3389/fpsyg.2017.01609

Ryan, T., Chester, A., Reece, J., \& Xenos, S. (2014). The uses and abuses of Facebook: A review of Facebook addiction. Journal of Behavioral Addictions, 3(3), 133-148. doi: 10.1556/JBA.3.2014.

Saied, S. M., Elsabagh, H. M., \& El-Afandy, A. M. (2016). Internet and facebook addiction among Egyptian and Malaysian medical students: A comparative study, Tanta University, Egypt. International Journal of Community Medicine and Public Health, 3(5), 1288-1297. doi:10.18203/23946040.ijcmph20161400

Sallis, M. (2013). An exploratory study of internet and social media addiction in Millennials. (Honors Projects: 674). Retrieved from https://repository.tcu.edu/handle/116099117/7308

Saraji, J. H., \& Fini, A. A. S. (2017). Examine the relationship between internet addiction with academic achievement and mental health of high school students in Bandar Abbas. South Journal of Educational Psychology and Counseling, 3(1), 97-101.

Sarıçam, H., Tarhan, D. \& Soyuçok, E. (2015, September). The examination of the relations between social anxiety, loneliness, Facebook ${ }^{\circledR}$ addiction and depression with multiple regression analysis. Paper presented at the Third International Instructional Technologies \& Teacher Education Symposium, Trabzon, Turkey. doi: 10.13140/RG.2.1.1024.8561

Sarıçam, H., Yaman, E., \& Çelik, İ. (2016). The mediator effect of loneliness between percieved social competence and cyber bullying in Turkish adolescents. International Journal of Progressive Education (IJPE), 12(1), 99-107.

Scealy, M., Phillips, J. G., \& Stevenson, R. (2002). Shyness and anxiety as predictors of patterns of internet usage. Cyber Psychology \& Behavior, 5(6), 507-515. doi: 10.1089/109493102321018141

Schermelleh-Engel, K., Moosbrugger, H., \& Müller, H. (2003). Evaluating the fit of structural equation models: Tests of significance and descriptive goodness-of-fit measures. Methods of Psychological Research Online, 8(2), 23-74.

Seabrook, E. M., Kern, M. L., \& Rickard, N. S. (2016). Social networking sites, depression, and anxiety: A systematic review. JMIR Mental Health, 3(4), e50. doi:10.2196/mental.5842

Shaw, M., \& Black, D. (2008) Internet addiction: Definition, assessment, epidemiology and clinical management. CNS Drugs, 22(5), 353-365.

Shaw, A. M., Timpano, K. R., Tran, T. B., \& Joormann, J. (2015). Correlates of Facebook usage patterns: The relationship between passive Facebook use, social anxiety symptoms, and brooding. Computers in Human Behavior, 48, 575-580. doi: 10.1016/j.chb.2015.02.003

Shensa, A., Escobar-Viera, C. G., Sidani, J. E., Bowman, N. D., Marshal, M. P., \& Primack, B. A. (2017). Problematic social media use and depressive symptoms among U.S. young adults: A nationallyrepresentative study. Social Science \& Medicine, 182, 150-157. doi: 10.1016/j.socscimed.2017.03.061

Sioni, S. R., Burleson, M. H., \& Bekerian, D. A. (2017). Internet gaming disorder: Social phobia and identifying with your virtual self. Computers in Human Behavior, 71, 11-15. doi:10.1016/j.chb.2017.01.044

Soğuksu, Y. B. \& Alıcı, D. (2016). Eşdeğer yarılar güvenirliğinin farklı homojenlik düzeylerindeki örneklem büyüklüklerinde, test uzunluğuna, yarıya bölme yöntemlerine ve güvenirlik kestirme tekniklerine göre incelenmesi. Mersin Üniversitesi Ë̆itim Fakültesi Dergisi, 12(1), 237-252.

Soyer, R. B., Rovenpor, J. L., Kopelman, R. E., Mullins, L. S., \& Watson, P. J. (2001). Further assesment of the construct validity of four measures of narcissism: Replication and extension. Journal of Psychology, 135(3), 245-258. doi:10.1080/00223980109603695

Starcevic, V., \& Aboujaoude, E. (2017). Internet addiction: Reappraisal of an increasingly inadequate concept. CNS Spectrums, 22(1), 7-13. doi: 10.1017/S1092852915000863 
Stevens, J. P. (2002). Applied multivariate statistics for the social sciences. New Jersey: Lawrance Erlbaum Association, Inc.

Şahin, C., \& Yağc1, M. (2017). Sosyal Medya Bağımlılı̆̆ Ölçeği-Yetişkin Formu: Geçerlilik ve güvenirlik çalışması. Ahi Evran Üniversitesi Kırşehir Eğitim Fakültesi Dergisi (KEFAD), 18(1), 523-538.

Şencan, H. (2005). Sosyal ve davranışsal ölçümlerde güvenilirlik ve geçerlilik. Ankara. Seçkin.

Şimşek, E., \& Balaban Sali, J. (2014). The role of internet addiction and social media membership on university students' psychological capital. Contemporary Educatıonal Technology, 5(3), 239-256.

Şişman Eren, E. (2014). Sosyal Medya Kullanım Amaçları Ölçeğinin geliştirilmesi ve bazı kişisel değişkenlere göre incelenmesi. Hacettepe Üniversitesi Eğitim Fakültesi Dergisi (H. U. Journal of Education), 29(4), 230-243.

Tabachnick, B. G., \& Fidell, L. S. (2014). Using multivariate statistics (6th ed.). USA: Pearson Education Limited.

Tandoc, E. C., Ferrucci, P., \& Duffy, M. (2015). Facebook use, envy, and depression among college students: Is Facebooking depressing? Computers in Human Behavior, 43, 139-146. doi: 10.1016/j.chb.2014.10.053

Tavernier, R., \& Willoughby, T. (2014). Sleep problems: Predictor or outcome of media use among emerging adults at university? Journal of Sleep Research, 23(4), 389-396. doi:10.1111/jsr.12132

Tavşancıl, E. (2014). Tutumların ölçülmesi ve SPSS ile veri analizi (5.Baskı). Ankara: Nobel Akademik.

Tekeş, B., \& Hasta, D. (2015). Özgecilik Ölçeği: Geçerlik ve güvenirlik çalışması. Nesne Psikoloji Dergisi (NPD), 3(6), 55-75. doi: 10.7816/nesne-03-06-03

Thompson, B. (2004). Exploratory and confirmatory factor analysis understanding concepts and applications. Washington, DC: APA.

Torrente, E., Piqueras, J. A., Orgilés, M., \& Espada, J. P. (2014). Association of internet addiction with social anxiety and lack of social skills in Spanish adolescents. Terapia Psicológica, 32, 175-184. doi:10.4067/S0718-48082014000300001

Traub, R. E. (1994). Reliability for the social sciences. London: Sage.

Tuğut, N., \& Gölbaşı, Z. (2010). Cinsel Yaşam Kalitesi Ölçeği-Kadın Türkçe versiyonunun geçerlik ve güvenirlik çalışması. Cumhuriyet Tıp Dergisi, 32, 172-180.

Türkyılmaz, M. (2015). Facebook Bağımlılığı Ölçeğinin Türkçeleştirilmesi ve Facebook bağımlılığının okuma becerisine etkisi. International Journal of Social Science, 36, 265-280. doi: 10.9761/JASSS2942

Van Rooij, A. J., Schoenmakers, T. M., van den Eijnden, R. J. J. M., \& Van de Mheen, D. (2010). Compulsive internet use: The role of online gaming and other internet applications. The Journal of Adolescent Health, 47(1), 51-57. doi: 10.1016/j.jadohealth.2009.12.021.

van den Eijnden, R. J. J. M., Lemmens, J. S., \& Valkenburg, P. M. (2016). The Social Media Disorder Scale. Computers in Human Behavior, 61(2016), 478-487. doi: 10.1016/j.chb.2016.03.038

Vannucci, A., Flannery, K. M., \& Ohannessian, C. M. (2017). Social media use and anxiety in emerging adults. Journal of Affective Disorders, 207, 163-166. doi:10.1016/j.jad.2016.08.040

Velicer, W. F., \& Fava, J. L. (1998). Effects of variable and subject sampling on factor pattern recovery. Psychological Methods, 3(2), 231-251. doi: 10.1037/1082-989X.3.2.231

Veneziano, L., \& Hooper, J. (1997). A method for quantifying content validity of health-related questionnaires. American Journal of Health Behavior, 21(1), 67-70.

Veronica, S. A., \& Samuel, A. U. (2015). Social media addiction among adolescents with special reference to Facebook addiction. IOSR Journal Of Humanities And Social Science (IOSR-JHSS), 4, 72-76. Retrieved from http://www.iosrjournals.org/iosr-jhss/papers/Conf.17004/Volume-4/15.\%2072-76.pdf

Vieira, A. L. (2011). Preparation of the analysis. Interactive LISREL in practice. London: Springer

Vishwanath, A. (2015). Habitual Facebook use and its impact on getting deceived on social media. Journal of Computer-Mediated Communication, 20(1), 83-98. doi: 10.1111/jcc4.12100

Walker, D. A. (2006). A comparison of the Spearman-Brown and Flanagan-Rulon formulas for split half reliability under variance parameter conditions. Journal of Modern Applied Statistical Methods, 5(2), 443-451.

Wang, M., \& Qi, W. (2017). Harsh parenting and problematic internet use in Chinese adolescents: Child emotional dysregulation as mediator and child forgiveness as moderator. Computers in Human Behavior, 77, 211-219. doi: 10.1016/j.chb.2017.09.005

Wegmann, E., Stodt, B., \& Brand, M. (2015). Addictive use of social networking sites can be explained by the interaction of internet use expectancies, internet literacy, and psychopathological symptoms. Journal of Behavioral Addictions, 4(3), 155-162. doi: 10.1556/2006.4.2015.021

Yen, J. Y., Ko, C. H., Yen, C. F., Wu, H. Y., \& Yang, M. J. (2007). The comorbid psychiatric symptoms of internet addiction: Attention deficit and hyperactivity disorder (ADHD), depression, social phobia, and hostility. Journal of Adolescent Health, 41(1), 93-98. 
Young, K. S. (1998a). Internet addiction: The emergence of a new clinical disorder. CyberPsychology \& Behavior, 1(3), 237-244.

Young, K. S. (1998b). Caught in the net: How to recognize the signs of internet addiction and a winning strategy for recovery. New York: John Wiley \& Sons.

Yuan, K., Qin, W., Wang, G., Zeng, F., Zhao, L., Yang, X. ... Tian, J. (2011). Microstructure abnormalities in adolescents with internet addiction disorder. PLOS ONE, 6(6), e20708. doi: 10.1371/journal.pone.0020708

\section{EXTENDED ABSTRACT}

\section{Introduction}

There is current evidence that social media disorder is a growing problem, especially among children and adolescents. However, there is no comprehensive instrument for measuring social media addiction in Turkey. The current study, therefore, aimed to examine the psychometric properties of Turkish culture and to test the reliability and validity of a short and easy to administer Social Media Disorder (SMD-9) Scale that contains a clear diagnostic cutoff point to discriminate between disordered (i.e. addicted) and high-engaging non-disordered social media users.

\section{Method}

Data was obtained from $586(202+204+180)$ adolescents who volunteered to take part in this study. They were selected via convenience sampling technique. The participants were all aged between 13 and 18. There were 113 girls and 89 boys in the first study group, 108 girls and 96 boys in the second study group, 66 girls and 114 boys in the third study group. 549 of the adolescents have at least one account on Facebook, WhatsApp, Instagram, Twitter, etc. social media sites.

The Social Media Disorder Scale (SMDS-9): The original form of the SMDC-9 was developed by Van den Eijnden, Lemmens, and Valkenburg (2016). In sample 1, the unconstrained first-order structural 9-item model using Mean- and Variance-adjusted Weighted Least Square (WLSMV) estimators yielded a good fit, $\mathrm{c}^{2}(27, \mathrm{n}=724)=24.846, \mathrm{p}=0.58, \mathrm{CFI}=1.000$, RMSEA $=0.000$ (90\% CI:0.000-0.026). This short SMD scale was strongly correlated with the 27 -item SMD scale $(r=0.89, \mathrm{p}<0.001)$ and showed good reliability with a Cronbach's alpha of $0.81(\mathrm{M}=1.22, \mathrm{SD}=$ 1.87). The long (27-item) and short (9-item) versions of the SMD scale both showed large positive correlations with compulsive Internet use $(r>0.50)$ and medium to large correlations with selfdeclared social media addiction, $(r>0.48)$, indicating satisfactory convergent validity. Test-retest reliability of the 9-item short SMD scale was assessed among the 238 adolescents who participated in both the first and the second online survey (with an interval of 2 months between these two surveys). A moderate degree of reliability was found between the first and second SMD scales. The Pearson correlation between both scales was $0.50, \mathrm{p}<0.001$.

Young's Internet Addiction Test-Short Form: The original of the Internet Addiction Scale was developed by Young (1998a; 1998b) and its short version was made by Pawlikowski AltstötterGleich, and Brand (2013). Kutlu et al. (2016) undertook the Turkish adaptation of this scale. The scale consists of 12 items, and each item was presented on a 5-point, Likert-type scale $(1=$ never, through to $5=$ =always).

Smart Phone Addiction Scale-Short Form for Adolescent: The original of the Smart Phone Addiction Scale was developed by Kwon, Kim, Cho, and Yang (2013) and its Turkish adaptation was made by Akın et al. (2014). The scale consists of 10 items, and each item was presented on a 5-point, Likerttype scale ( $1=$ largely untrue, $5=$ largely true).

With Regina Van den EIJNDEN, one of the developers for the adaptation study of the SMDC, was contacted via e-mail and permission for the adaptation to Turkish was obtained (Date 28 February 2017). The psychometric properties of the Turkish SMDC-9 were examined via language content validity, structural validity (EFA and CFA), criterion-related validity, discrimination validity, 
internal consistency, split half reliability, and item analysis. Generally, for GFI, CFI, NFI, RFI, and IFI indices, values greater than .90 , for RMSEA and RMR, values less than .05 are taken as criterion. $\mathrm{p}<.01$ is based as the level of significance. For the validity and reliability analysis of the SMDC-9, a statistical computer program package was used.

\section{Results and Discussion}

According to Lawshe technique, language Content Validity Index (CVI) values were calculated between 0.78 and +1.00 and it was found that the index is statistically significant. Moreover, according to Davis technique, content validity index (CVI) scores were calculated between 0.89 and 1.00 .

As a result of the explanatory factor analysis applied to data from the study conducted on study group 1, Kaiser- Meyer-Olkin (KMO) measure of sampling adequacy was .84 and there was a significant result on Bartlett's test of Sphericity $\chi^{2}=450.74(\mathrm{df}=36, \mathrm{p}<.001)$. One-factor structure explained $48.11 \%$ of the total variance, and the factor loadings of the items ranged between .28 and .81 .

The results of confirmatory factor analysis indicated that the model had good fit $\chi^{2} / \mathrm{df}=1.87$, RMSEA=.066, CFI=.98, GFI=.98, IFI=.98, NFI=.96, RFI=.97, and SRMR=.039 (Sample 2). Factor loadings ranged from .35 to .76. In the concurrent validity, the Social Media Disorder Scale-9 had significant relationships with Young's Internet Addiction Test-Short Form and Smart Phone Addiction Scale-Short Form for Adolescent ( $r=.64, .66$, respectively).

In canonical discriminant analysis, independent variable contributing most to accurate classification of social media addiction was "smart phone addiction". It was followed by "internet addiction". Cronbach alpha internal consistency coefficient was found as $\alpha=.75$ (Sample 3).

Guttman split-half reliability coefficient was found as .64. Corrected item-total correlations ranged from .29 to .73 . According to t-test results concerning the significance of the difference between the upper and lower $27 \%$ of the total mean scores, there is a significant difference in favor of the upper group. Overall results demonstrated that Social Media Disorder Scale-9 can generate reliable and valid measurements to be used for assessing social media addictions of adolescents in Turkey. 
Sarıçam, H., Adam Karduz, F. F. / Sosyal Medya Kullanım Bozukluğu Ölçeğinin Türk Kültürüne Uyarlanması: Geçerlik ve Güvenirlik Çalışması

\section{Ekler}

\section{Sosyal Medya Kullanım Bozukluğu Ölçeği-9}

\begin{tabular}{|c|c|c|c|c|c|c|c|c|}
\hline $\begin{array}{l}\text { Son } 1 \text { yıl içerisinde } \\
\text { Aşağıdaki } 9 \text { tane ifadeyi ne sıklıkla yaşadı̆̆ınız karşısında bulunan " } \\
\text { "1=Günde bir kereden daha az", "2=Günde } \mathbf{1 - 2} \text { defa", "3=G } \\
\mathbf{6 - 1 0} \text { defa", "5= Günde } \mathbf{1 1 - 2 0} \text { defa", "6= Günde } \mathbf{2 1 - 4 0} \text { defa" } \\
\text { fazla" anlamına gelmektedir) arasındaki rakamları (X) işareti koyara } \\
\text { rakamı işaretleyiniz ve boş bırakmayını. }\end{array}$ & & & & & & & & \\
\hline $\begin{array}{l}\text { 1.Sosyal medyayı tekrar kullanabileceğin zamana kadar kendini sürekli } \\
\text { olarak başka hiçbir şey düşünemez halde buldun mu? }\end{array}$ & 0 & 1 & 2 & 3 & 4 & 5 & 6 & 7 \\
\hline $\begin{array}{l}\text { 2.Sosyal medyada daha fazla zaman harcamak istediğin için kendini } \\
\text { sürekli memnuniyetsiz (tatmin olmamış) hissettin mi? }\end{array}$ & 0 & 1 & 2 & 3 & 4 & 5 & 6 & 7 \\
\hline 3.Sosyal medyayı kullanmadığında kendini sıklıkla kötü hissettin mi? & 0 & 1 & 2 & 3 & 4 & & 6 & 7 \\
\hline $\begin{array}{l}\text { 4.Sosyal medyada daha az zaman harcamaya çalıştın ama başaramadın } \\
\text { mı? }\end{array}$ & 0 & 1 & 2 & 3 & 4 & 5 & 6 & 7 \\
\hline $\begin{array}{l}\text { 5.Olumsuz duygulardan kaçmak için sosyal medyayı sıklıkla kullandın } \\
\text { mı? }\end{array}$ & 0 & 1 & 2 & 3 & 4 & 5 & 6 & 7 \\
\hline $\begin{array}{l}\text { 6.Sosyal medya kullanımı yüzünden başkalarıyla sürekli olarak } \\
\text { tartışma yaşadın mı? }\end{array}$ & 0 & 1 & 2 & 3 & 4 & 5 & 6 & 7 \\
\hline $\begin{array}{l}\text { 7.Anne babana veya arkadaşlarına sosyal medyada geçirdiğin süreyle } \\
\text { ilgili sürekli yalan söyledin mi? }\end{array}$ & 0 & 1 & 2 & 3 & 4 & 5 & 6 & 7 \\
\hline $\begin{array}{l}\text { 8.Sosyal medya kullanmak istediğin için diğer aktiviteleri (örn. hobiler, } \\
\text { spor) sürekli olarak ihmal ettin mi? }\end{array}$ & 0 & 1 & 2 & 3 & 4 & 5 & 6 & 7 \\
\hline $\begin{array}{l}\text { 9.Anne baban ve kardeşlerinle sosyal medya kullanımı yüzünden ciddi } \\
\text { çatışmalar yaşadın mı? }\end{array}$ & 0 & 1 & 2 & 3 & 4 & $J$ & 6 & 7 \\
\hline
\end{tabular}

Not: Kaynak gösterilmesi koşuluyla ölçek maddeleri kullanılabilir. 